J. Clin. Chem. Clin. Biochem.

Vol. 20, 1982, pp. 537-552

\title{
Zur Bestimmung der katalytischen Aktivität der Lipase mit 2,3-Dimercapto-1-propanol-tributyrat als Substrat
}

Von W. Rick und M. Hockeborn

Institut für Klinische Chemie und Laboratoriumsdiagnostik der Universität Düsseldorf

(Eingegangen am 28. Oktober 1981/6. Januar 1982)

Zusammenfassung: In der vorliegenden Arbeit wurde der von Kurooka et al. (J. Biochem. Tokyo 81, 361-369

(1977)) ausgearbeitete Zweipunkttest zur Bestimmung der Lipase mit 2,3-Dimercapto-1-propanol-tributyrat als Substrat und mit Ellmans Reagens als Akzeptor der freigesetzten Thiolgruppen eingehend untersucht. Bei der Prüfung des zeitlichen Ablaufs der enzymatischen Hydrolyse des Substrats wurde eine ausgeprägte lag-Phase beobachtet, die durch Zusatz von Na-Glykocholat beeinflußbar ist. Zwischen der eingesetzten Serummenge und der Konzentration der freigesetzten SH-Gruppen besteht keine Proportionalität. Die von den Autoren empfohlene Vorinkubation der Probe mit dem Esteraseinhibitor Phenylmethylsulfonylfluorid reicht zur vollständigen Hemmung der Serumesterasen nicht aus. Die Wirkung des im Testsystem enthaltenen Na-Dodecylsulfats ist nicht geklärt; im kontinuierlichen titrimetrischen Test mit Triolein als Substrat wirkt die Substanz als starker Hemmstoff der Lipase. In Vergleichsuntersuchungen an 104 Seren wurden signifikante Abweichungen von den Ergebnissen der Titrimetrie gefunden. Möglichkeiten zu einer grundlegenden Verbesserung des Testsystems mit Thioestem als Substrat werden diskutiert.

\section{Determination of lipase with 2,3-dimercapto-1-propanol-tributyrate as substrate}

Summary: The two point test for the determination of lipase by Kurooka et al. (J. Biochem. Tokyo 81, 361-369 (1977)) was studied in detail. This procedure uses 2,3-dimercapto-1-propanol-tributyrate as substrate and Ellman's reagent as an acceptor for the released thiol groups. The time course of the enzymic hydrolysis of the substrate showed a pronounced lag phase, which can be influenced by sodium glycocholate. There is no proportionality between the quantity of added serum and the concentration of released thiol groups. Preincubation of the sample with the esterase inhibitor, phenylmethylsulphonylfluoride, as recommended by the authors, does not completely inhibit the serum esterase activity. The action of sodium dodecyl sulphate, which is included in the test system, is not explained; in the continuous titrimetric test with triolein as substrate, it acts as a powerful lipase inhibitor. Using 104 serum samples, significant differences were found between the results from this method and those obtained by the titrimetric determination of lipase. Possible fundamental improvements of this test system, using thioesters as substrate, are discussed.

\section{Einführung}

Definitionsgemäß hydrolysiert Lipase (Triacylglycerol acyl hydrolase, EC 3.1.1.3) Triglyceride, während Carboxylesterasen Fettsäureester spalten. Eine Reihe von Substanzen - z.B. Tributyrin - wird von Lipasen und Esterasen umgesetzt. Die Verwendung derartiger Substrate zur quantitativen Bestimmung der Lipase im Serum ist problematisch, da eine vollständige Hemmung aller Esterasen ohne Beeinflussung der Lipase erforderlich ist. Kurooka et al. (1) schlugen vor, das von ihnen synthetisierte 2,3-Dimercapto-1-propanol-tributyrat in einem photometrischen Test zur Messung der Pankreaslipase zu benutzen. Durch Zusatz von Phenylmethylsulfonylfluorid sollen die im Serum enthaltenen Esterasen gehemmt werden. Wir prüften das neue Verfahren an zahlreichen Seren sowie mit reiner Carboxylesterase und führten Vergleichsuntersuchungen mit dem kontinuierlichen titrimetrischen Test (2) aus.

\footnotetext{
Material

Enzymc

Die folgenden Enzympräparationen wurden cingesetzt:

"Lipase-Standard" (Sollwert $452 \mathrm{U} / \mathrm{l}$ ).

aus der Testpackung Lipase, turbidimetrischer Test, Bochringer Mannhcim, Bestell-Nr. 263346.

Esturase (Carboxylester hydrolase, EC 3.1.1.1),

aus Schweineleber, Boehringor Mannheim, Bestcll-Nr. 104698 , spezifische Aktivität ctwa $100 \mathrm{U} / \mathrm{mg}\left(25^{\circ} \mathrm{C}\right)$ gegen Buttersïurecthylestcr als Substrat.
} 


\section{Probenmaterial}

Bei den verwendeten Proben handelte es sich um:

Seren von Gesunden,

Seren von Patienten mit akuten oder chronischen Pankreaserkrankungen,

Seren, die etwa 10 Minuten nach i.v. Injektion von 5000 I.E. Heparin von Gesunden gewonnen wurden,

Seren, in denen die Pankreaslipase durch zweistündige Inkubation bei $56^{\circ} \mathrm{C}$ vollständig inaktiviert worden war; dies wurde im titrimetrischen Test mit Triolein als Substrat nachgewiesen.

\section{Reagentien}

\section{Lipase Kit „Marupi“}

Die Reagentienkombination enthält nach Angaben des Herstellers:

\section{Substratlösung:}

$20 \mathrm{mmol} / \mathrm{l}$ 2,3-Dimercapto-1-propanol-tributyrat und $20 \mathrm{mmol} / \mathrm{l}$ Na-Dodecylsulfat in Ethanol.

2. Farbreagens-Stammlösung:

3,0 mmol/1 5,5'-Dithio-bis(2-nitrobenzoat) in 0,1 mol/1 TrisHCl-Puffer, pH 8,5.

In kleinen Portionen abfüllen und bei $-20^{\circ} \mathrm{C}$ lagern. Die Lösung ist nur verwendbar, wenn die Absorption bei $412 \mathrm{~nm}$ - gegen bidest. Wasser gemessen - unter 1,0 liegt.

3. Farbreagens-Gebrauchslösung:

1 Teil Farbreagens-Stammlösung

+1 Teil $1 \mathrm{~mol} / 1$ Tris-HCl-Puffer, pH 8,5

+8 Teile bidest. Wasser

vor Gebrauch mischen.

4. Inhibitorlösung:

$20 \mathrm{mmol} / 1$ Phenylmethylsulfonylfluorid in Ethanol.

Außerdem wurden benutzt:

5. Aceton zur Analyse, Merck 14.

6. Dimethylsulfoxid für die Spektroskopie, Merck 2950.

\section{Für Modifikationen des Testansatzes}

Zusätzlich wurden von uns verwendet:

7. 2,3-Dimercapto-1-propanol-tributyrat, rein, frei von 2,3-Dimercapto-1-propanol.

Wir danken Herrn Dr. S. Kurooka für die entgegenkommende Überlassung der Reinsubstanz.

8. 2,3-Dimercapto-1-propanol, für die Komplexometrie, Merck 3409.

9. Tris(hydroxymethyl)-aminomethan zur Analyse, Merck 8382. 10. Glykocholsäure purum, über $95 \%$, Fluka 50540, Charge 19579.

11. Ethylendinitrilotetraessigsäure (EDTA), Dinatriumsalz, Dihydrat, zur Analyse, Merck 8418.

12. 5,5'-Dithio-bis(2-nitrobenzoesäure) (Ellmans Reagens), kristallisiert, Boehringer 104477.

13. Dodecylhydrogensulfat, Natriumsalz, für Tensiduntersuchungen, Merck 2969.

14. Methanol, zur Analyse, Merck 6009.

15. Ethanol absolut, zur Analyse, Merck 972.

16. Propanol-(2), zur Analyse, Merck 9634.
17. Butanol-(1), zur Analyse, Merck 1990.

18. iso-Butanol, zự Analyse, Merck 984.

19. Benzylalkohol, für die Chromatographie, Merck 9626.

20. Dichlormethan, zur Analyse, Merck 6050.

21. Chloroform, zur Analyse, Merēk 2445.

22. N.N-Dimethylformamid, für die Spektroskopie, Merck 2937.

23. N.N-Diethylacetamid, zur Synthese, Merck 3214.

24. Hexamethylphosphorsäuretriamid, für die Spektroskopie, Merck 4563.

25. Polyethylengly col-monol $p$-(1,1,3,3-tetramethylbutyl)phenyllether (Triton X-100), fưr die Gaschromatographie, Merck 12298.

26. Essigsäure min. 96\%, zur Analyse, Merck 90062.

27. Substratlösungen:

$20 \mathrm{mmol} / 1$ 2,3-Dimercapto-1-propanol-tributyrat in abs. Ethanol. $20 \mathrm{mmol} / 1$ 2,3-Dimercapto-1-propanol-tributyrat $+20 \mathrm{mmol} / 1$ Na-Dodecylsulfat in Ethanol.

2,42 $\mathrm{mmol} / 1$ 2,3-Dimercapto-1-propanol-tributyrat mit

$1,5 \mathrm{mmol} / 1 \mathrm{Na}-G l y k o c h o l a t$ in $0,1 \mathrm{~mol} / 1$ Tris-HCl-Puffer, $\mathrm{pH} 8,8$.

28. $58,5 \mathrm{mmol} / 1$ EDTA in bidest. Wasser.

29. 0,3 mmol/1 5,5'-Dithio-bis(2-nitrobenzoat) in 0,1 mol/1 Tris-HCl-Puffer, $\mathrm{pH}$ 8,8.

\section{Für den kontinuierlichen titrimetrischen Test}

Hierzu wurden die bereits 1976 (2) aufgeführten Reagentien benutzt. Zusätzlich wurden verwendet:

30. 0,2 1/1 2,3-Dimercapto-1-propanol-tributyrat in $100 \mathrm{~g} / 1$ Gummi arabicum in bidest. Wasser; die Emulsion wurde auf einen pH-Wert von etwa 9,0 eingestellt.

31. 0,2 l/1 Tween 20 (Merck-Schuchardt 822184) in bidest. Wasser; die Lösung wurde auf einen pH-Wert von etwa 9,0 eingestellt.

32. Dodecylhydrogensulfat, Natriumsalz, Merck 2969, Lösungen von 400,40 und $4 \mathrm{mmol} / 1$ in bidest. Wasser.

33. Phenylmethylsulfonylfluorid, $20 \mathrm{mmol} / 1$ in Ethanol (aus der Lipase-Testpackung „Marupi").

s...

\section{Methodik}

Verwendung der Testpackung „Marupi“

Prinzip

Zur Bestimmung der Lipase dient der dem Tributyrin analoge Buttersäureester des 2,3-Dimercapto-1-propanols als Substrat. In einer anschließenden nichtenzy matischen Indikatorreaktion setzt das entstandene 2,3-Dimercapto-1-propanol aus 5,5'-Dithiobis(2-nitrobenzoat) gelbgefärbtes 2-Nitro-5-mercaptobenzoat frei (3), dessen Konzentration photometrisch gemessen wird.

$$
\text { (siehe Seite } 539 \text { oben) }
$$

Durch Vorinkubation mit Phenylmethylsulfonylfluorid wird versucht, die im Serum enthaltenen Esterasen vollständig zu hemmen (1).

Da das Substrat nur wenig wasserlöslich ist, zeigt der Testansatz eine deutliche Trübung. Damit eine photometrische Messung möglich wird, ist es erforderlich, zum Stoppen der Enzymreaktion nach einer definierten Inkubationszeit ein Lösungsmittel zu verwenden, das gleichzeitig eine Klärung des Ansatzes bewirkt. 
Von den Autoren wird folgendes Reaktionsschema angegeben (1):

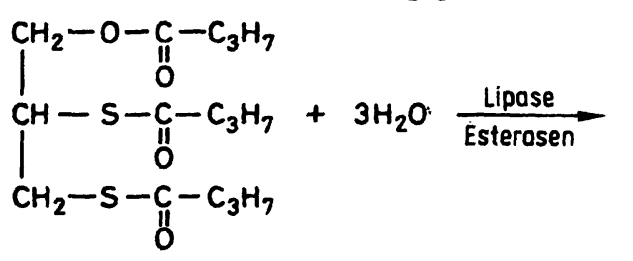<smiles>O=C(O)c1ccccc1</smiles>

\section{2,3-Dimer-} capto-1propanoltributyrat

2,3-Dimer- Buttersäure
capto-1-
propanol<smiles>OCC(S)CS</smiles>

2,3-Dimercapto-1propanol
$+2$<smiles>COC(=O)c1cc(SSc2ccc([N+](=O)[O-])c([N+](=O)[O-])c2)ccc1C(=O)[O-]</smiles>

\section{5,5'-Dithio-bis(2-nitrobenzoat)}<smiles>[Z]Sc1ccc([N+](=O)[O-])c(C(=O)[O-])c1</smiles>

2-Nitro-5mercaptobenzoat<smiles>O=C([O-])c1cc(SSc2ccc([N+](=O)[O-])c([N+](=O)[O-])c2)ccc1SSCCCO</smiles>

1-Propanol-2,3-bis (5'-dithio-2-nitrobenzoat)

\section{Ausfuihrung}

Um Vergleiche mit anderen Bestimmungsmethoden (2) zu ermöglichen, wurden die Messungen bei $25^{\circ} \mathrm{C}$ ausgeführt. Wenn nicht anders angegeben, wurde nach folgendem Schema verfahren:

Reagensröhrchen (Doppel- bis Vierfachbestimmungen)

$\begin{array}{cc}\text { Hauptwert } & \text { Leerwert } \\ 50 \mu \mathrm{l} & 50 \mu \mathrm{l} \\ 1,0 \mathrm{ml} & 1,0 \mathrm{ml} \\ & \text { mischen } \\ 20 \mu \mathrm{l} & 20 \mu \mathrm{l} \\ \ddots & \text { mischen }\end{array}$

sulfonylfluorid

(Lösung 4)

10 min Wasserbad $25^{\circ} \mathrm{C}$

Substratlösung

2,3-Dimercapto-

1-propanol-

tributyrat

(Lösung 1)

(mit und ohne

Zusatz von

Na-Glykocholat)

Aceton bzw.

Dimethylsulfoxid

$100 \mu \mathrm{l}$

im Abstand von $15 \mathrm{~s}$ im Abstand von zusetzen und Röhr- $15 \mathrm{~s}$ Röhrchen chen nach Mischen ins Wasserbad wieder ins Wasserbad stellen stellen

$30 \mathrm{~min}$ Wasserbad $25^{\circ} \mathrm{C}$

$2,0 \mathrm{ml}$

$2,0 \mathrm{ml}$

Substratlösung

2,3-Dimercapto-

1-propanol-

tributyrat (Lösung 1)

(mit und ohne

Zusatz von

Na-Glykocholat)
Die Ablesung erfolgte am Spektrallinienphotometer Eppendorf, Filter $\mathrm{Hg} 405$ bzw. $436 \mathrm{~nm}$, in Küvetten von $1 \mathrm{~cm}$ Schichtdicke. $\mathrm{Da}$ die Farbintensität der Ansätze ständig zunimmt, ist es erforderlich, Haupt- und Leerwerte so schnell wie möglich in engem zeitlichen Zusammenhang abzulesen. Ein wechselndes Einfüllen von Haupt- und Leerwerten würde einen starken Verschleppungsfehler ergeben - zumal die Ansätze mit Aceton kein Vorspülen erlauben -, daher wird mit 3 Küvetten absolut gleicher Lichtdurchlässigkeit gearbeitet.

\section{Berechnung}

Von Kurooka et al. (1) wird eine Einheit als Absorptionsdifferenz zwischen Haupt- und Leerwert von 0,001 pro $50 \mu$ l Probe und 30 min Inkubation bei $30^{\circ} \mathrm{C}$ definiert; hieraus ergibt sich ein Berechnungsfaktor von 1000.

Die von den Autoren (1) vorgeschlagene Umrechnung in U/1, definiert als $\mu \mathrm{mol}$ freigesetzte SH-Gruppen pro Minute, ist nicht gerechtfertigt, da die Enzymreaktion während der Inkubationszeit nicht geradlinig verläuft.

Eigene Modifikationen des Tests mit 2,3-Dimercapto-1-propanol-tributyrat

Änderungen im Arbeitsablauf sind jeweils im Text erwähnt.

Kontinuierlicher titrimetrischer Test

Die Methodik entsprach den Angaben von 1976 (2). In gleicher Weise wie die Triolein-Emulsion wurden eine 2,3-Dimercapto-1propanol-tributyrat-Emulsion in Gummi arabicum-Lösung und eine Tween 20-Verdünnung in bidest. Wasser als Substrate eingesetzt.

\section{Ergebnisse}

Verwendung der Testpackung „Marupi““

Farbstabilität der Farbreagens-Gebrauchslösung

bei etwa $3000 \mathrm{~min}^{-1}$ zentrifugieren (etwa $10 \mathrm{~min}$ bei Ansätzen mit Aceton, etwa $5 \mathrm{~min}$ bei Ansätzen mit Dimethylsulfoxid), klaren Uberstand sofort photometrieren (s.u.)
Zunächst wurde geprüft, ob die Lichtabsorption der Farbreagens-Gebrauchslösung in Abwesenheit von Enzym 
und Substrat konstant bleibt. Wie in Tabelle 1 gezeigt, kommt es bei Raumtemperatur unabhängig davon, ob die Lösung im Dunkeln oder bei Tageslicht aufbewahrt wird, zu einer kontinuierlichen Absorptionszunahme. Es ist daher notwendig, Haupt- und Leerwerte zeitlich absolut gleich zu behandeln.

Tab. 1. Farbstabilität der Farbreagens-Gebrauchslösung aus der Lipase-Testpackung „Marupi“".

\begin{tabular}{cll} 
Zeit & $\begin{array}{l}\text { Aufbewahrung der Farbreagens-Gebrauchslösung } \\
\text { im Dunkeln }\end{array}$ \\
bei Tageslicht \\
(min) & A $405 \mathrm{~nm}_{405 \mathrm{~nm}}$ \\
\hline 0 & 0,125 & 0,114 \\
20 & 0,135 & 0,125 \\
40 & 0,147 & 0,137 \\
60 & 0,158 & 0,147 \\
80 & 0,172 & 0,159 \\
100 & 0,184 & 0,173 \\
120 & 0,197 & 0,184 \\
180 & 0,238 & 0,222 \\
& $\Delta \mathrm{A}_{405 \mathrm{~nm}} / 180 \mathrm{~min}=$ & $\Delta \mathrm{A}_{405 \mathrm{~nm}} / 180 \mathrm{~min}=$ \\
& $0,113: 1$ & 0,108 \\
\hline
\end{tabular}

Verwendbarkeit der Farbreagens-Gebrauchslösung für die Indikatorreaktion

In Untersuchungen mit frisch angesetzter und 6 Stunden bei Raumtemperatur und Tageslicht aufbewahrter Farbreagens-Gebrauchslösung fanden wir an Normalseren und Proben von Patienten mit akuter Pankreatitis innerhalb des Meßfehlers gleiche Absorptionsdifferenzen zwischen Haupt- und Leerwerten.

\section{Verwendung verschiedener Lösungsmittel zum Abstoppen der Reaktion}

Das in der Originalmethode zur Beendigung der enzymatischen Reaktion verwendete Aceton ist leicht flüchtig, so daß es durch Verdunsten des Lösungsmittels während des Zentrifugierens und Meßvorgangs leicht zu einer unkontrollierten Absorptionszunahme der Ansätze kommen kann. Außerdem ergeben die ausgefallenen Serumbestandteile erst nach längerem Zentrifugieren ein festes Sediment. Weiter ist es erforderlich, stets mit trockenen Küvetten zu arbeiten. Wir suchten daher nach einer Substanz, die die enzymatische Reaktion hemmt und gleichzeitig die Serumproteine und das Substrat in Lösung hält.

Methanol, Ethanol, Propanol-(2), Butanol-(1), iso-Butanol, Benzylalkohol, Dichlormethan, Chloroform, N.N-Dimethylformamid, N.N-Diethylacetamid und Hexamethylphosphorsäuretriamid ergaben mehr oder weniger starke Niederschläge oder verhinderten die Farbentwicklung. Lediglich Dimethylsulfoxid führte zu klaren Lösungen und einer intensiven Gelbfärbung. Allerdings war es notwendig, die Ansätze mit $2,0 \mathrm{ml}$ Dimethylsulfoxid kurz zu zentrifugieren, um so eine Bläschenbildung beim Eingießen in die Küvette zu ver- meiden. Wir verwendeten bei unseren Versuchen neben Aceton auch Dimethylsulfoxid.

Wurden die Inkubationsansätze mit wäßrigen Triton $\mathrm{X}-100$-Verdünnungen versetzt, so ergaben sich klare Lösungen, jedoch keine konstanten Absorptionsdifferenzen.

Säuren, z.B. $1 \mathrm{~mol} / 1 \mathrm{bzw} .0,1 \mathrm{~mol} / 1 \mathrm{HCl}$ und Eisessig, führten zur Klärung der Testmischungen, verhinderten aber die Farbentwicklung.

\section{Absorptionsspektren bei Verwendung von Aceton und Dimethylsulfoxid als Lösungsmittel}

Das in der Indikatorreaktion entstehende 2-Nitro-5mercaptobenżoat absorbiert in wäßriger Lösung maximal bei $412 \mathrm{~nm}$ (3). Wir fanden, daß durch Zusatz von Aceton das Maximum auf 426-428 nm verschoben wird; bei $405 \mathrm{~nm}$ werden $82,7 \%$, bei $436 \mathrm{~nm} 98,4 \%$ der maximalen Absorption gemessen. Verwendet man Dimethylsulfoxid, so findet sich das Absorptionsmaximum bei $440-446 \mathrm{~nm}$; bei den Wellenlängen 405 und $436 \mathrm{~nm}$ werden $60,2 \%$ bzw. $98,6 \%$ der höchsten Absorption beobachtet.

\section{Farbentwicklung im Testansatz}

Um den Ablauf der Indikatorreaktion unter den Testbedingungen beurteilen zu können, wurde eine stark verdünnte Lösung von 2,3-Dimercap̄to-1-propanol $(0,2 \mathrm{mmol} / 1)$ in Tris-Puffer $\mathrm{pH} 8,8$ mit FarbreagensGebrauchslösung und Dimethylsulfoxid versetzt. Die gemessenen Absorptionen bleiben bis zu 30 Minuten konstant. Zusatz von Normalserum führte - bedingt durch die SH-Gruppen-haltigen Substanzen des Serums - zu einer geringgradig höheren Farb̈intènsität, die sich ebenfalls während 30 Minuten nicht änderte. In Ansätzen mit Substrat (2,3-Dimercapto-1-propanol-tributyrat) wurde weiterhin die Abhängigkeit der Farbentwicklung von der Zeit sowohl in Gegenwart von Normalserum als auch von Serum mit erhöhter katalytischer Aktivität nach Abstoppen mit Dimethylsulfoxid sowie Aceton geprüft. Es zeigte sich, daß die Farbintensität mit der Zeit langsam ansteigt, nach Abstoppen mit Dimethylsulfoxid etwa doppelt so stark wie in acetonhaltigen Testen. Außerdem war nachweisbar, daß das $\Delta \mathrm{A}$ bei Verwendung beider Lösungsmittel stetig zunahm, und zwar in Abhängigkeit von der Ausgangsabsorption; bei niedrigen Absorptionen ist der Fehler geringer als bei starker Gelbfärbung. Da es selbst bei Verwendung von Küvetten mit Schliffstopfen schwierig ist, das nach längerem Aufbewahren im Photometer an den Stopfen kondensierte Lösungsmittel wieder gleichmäßig mit dem Testansatz zu mischen, ist der Effekt nicht exakt quantitativ zu beschreiben. Bei einer Ausgangsabsorption um 1,0 beträgt die Zunahme des $\Delta \mathrm{A}$ in $100 \mathrm{~min}$ etwa $5 \%$. An dem Ausmaß der Absorptionsänderung mit der Zeit, deren Höhe bei Verwendung verschiedener Farbreagens-Gebrauchslösungen schwankt, sind vermutlich zahlreiche Urșachen be- 
teiligt: Die Instabilität der Farbreagens-Gebrauchslösung (s. Tab. 1), eine unvollständige Hemmung der enzymatischen Reaktion durch die Lösungsmittel, der Einfluß des Lösungsmittels auf die Indikatorreaktion und Substanzen in der Probe selbst. Der Anteil der Spontanhydrolyse des Substrats an dem Effekt ist nicht zu bestimmen. Es sei jedoch erwähnt, daß bei Verwendung von 2,3-Dimercapto-1-propanol-tributyrat wie auch von Tributyrin im kontinuierlichen titrimetrischen Test (200 $\mathrm{g} / 1$ in $100 \mathrm{~g} / \mathrm{l} \mathrm{Gummi}$ arabicum in bidest. Wasser) von uns nur eine sehr geringe Spontanhydrolysegeschwindigkeit gefunden wurde. Keine Rolle spielen Temperaturund Lichteinflüsse während der Farbentwicklung; dies konnte durch vergleichende Inkubation bei Raumtemperatur und $+50^{\circ} \mathrm{C}$ mit Tageslicht und im Dunkeln gezeigt werden. Die Ursache des Anstiegs der $\Delta \mathrm{A}$-Werte ist ungeklärt, zumal nach Fertigstellung der Ansätze in Haupt- und Leerwerten eine identische Zusammensetzung vorliegt. Um entsprechende Fehler im Verlauf der weiteren Untersuchungen zu vermeiden, wurde bei den verschiedenen Testserien darauf geachtet, daß der zeitliche Abstand zwischen Abstoppen der enzymatischen Reaktion und photometrischer Messung in einem engen Bereich konstant gehalten wurde. Außerdem erfolgten die Ablesungen der Haupt- und Leerwerte, wie bereits beschrieben, zur gleichen Zeit.

\section{Abhängigkeit der Reaktionsgeschwindigkeit von der Inkubationszeit}

Bei Zweipunkttesten ist es notwendig nachzuweisen, daß während der gesamten Inkubationszeit ein Substratumsatz mit konstanter Geschwindigkeit erfolgt. Die mit Serum eines Pankreatitispatienten gewonnenen Ergebnisse sind in Abbildung 1 dargestellt. Sowohl bei Verwendung von Aceton als auch von Dimethylsulfoxid zeigt sich, daß die Umsatzgeschwindigkeit zu Beginn der Reaktion deutlich geringer ist als im weiteren Verlauf. Gleiche Resultate finden sich bei Einsatz von Normalseren (Abb. 2). In Tabelle 2 sind die Ergebnisse zusammengestellt, die wir an einem „Lipase-Standard" und an Patientenproben mit unterschiedlicher katalytischer Aktivität an Lipase bei Abstoppen der Enzymreaktion nach 7,5, 15 und 30 Minuten erhielten. Bezogen auf die Absorptionsdifferenzen bei 30 Minuten Inkubation, die gleich $100 \%$ gesetzt wurden, liegen die nach 15 bzw. 7,5 Minuten gemessenen Farbintensitäten deutlich zu niedrig. Aus den aufgeführten Daten (Abb. 1 und 2, Tab. 2) ist ersichtlich, daß das Bestimmungsverfahren von Kurooka et al. (1) eine sogenannte lag-Phase zeigt, deren Dauer von der Aktivität der untersuchten Probe abhängt.

Wir prüften, ob dieses nichtlineare Verhalten dadurch bedingt sein könnte, daß im Testansatz keine Gallensäuren - wie sonst bei Bestimmungsverfahren zur Messung der Lipase erforderlich - enthalten sind. An Serum eines Patienten mit akuter Pankreatitis wurden

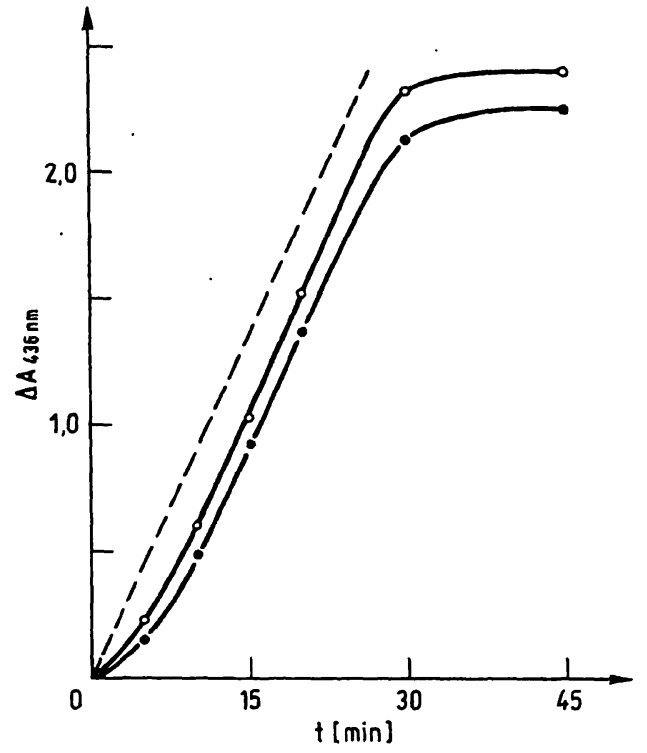

Abb. 1. Enzymatische Hydrolyse $\left(25^{\circ} \mathrm{C}\right)$ von 2,3-Dimercapto-1propanol-tributyrat in Abhängigkeit von der Inkubationszeit.

Im Test:

Serum eines Patienten mit akuter Pankreatitis

- Ansätze mit Aceton

○ـ— Ansätze mit Dimethylsulfoxid

- - - theoretischer Verlauf bei konstanter Umsatzgeschwindigkeit

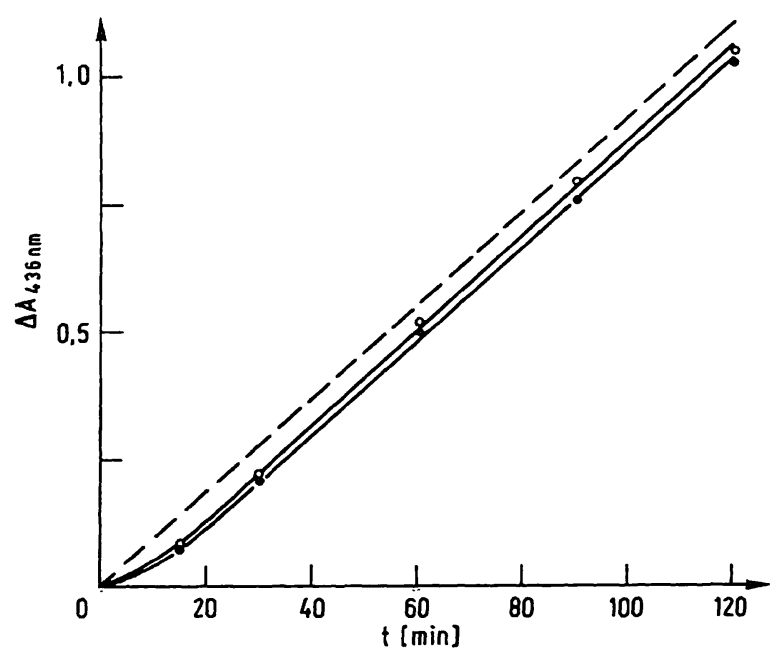

Abb. 2. Enzymatische Hydrolyse $\left(25^{\circ} \mathrm{C}\right)$ von 2,3-Dimercapto-1propanol-tributyrat in Abhängigkeit von der Inkubationszeit.

Im Test:

Normalserum

- Ansätze mit Aceton

○-o Ansätze mit Dimethylsulfoxid

-..- theoretischer Verlauf bei konstanter Umsatzgeschwindigkeit

die in Abbildung 3 und Tabelle 3 dargestellten Ergebnisse gewonnen. Es zeigt sich, daß bei diesem Serum die deutliche lag-Phase durch $\mathrm{Na}$-Glykocholat-Zusatz nicht beseitigt wird. Auch ist durch geringe Gallensalzkonzentrationen keine Aktivierung zu beobachten; oberhalb einer Endkonzentration von $3.0 \mathrm{mmol} / 1 \mathrm{Na}$-Glykocholat tritt eine Hemmung des Enzyms auf. Im Gegensatz dazu ließen sich bei der Analyse von Serum eines Ge- 
sunden Aktivierungseffekte durch $\mathrm{Na}$-Glykocholat in Konzentrationen von 1,25 bis etwa $4,0 \mathrm{mmol} / 1$ nachweisen (Abb. 4 und 5); außerdem nahm das Ausmaß der lag-Phase mit steigender Gallensalzkonzentration $a b$ (Abb. 4, Tab. 4). Weitere Untersuchungen an verschiedenen Seren zeigten, daß die in den einzelnen Proben gemessenen katalytischen Aktivitäten durch Zusatz von $\mathrm{Na}-$ Glykocholat ganz unterschiedlich beeinflußt werden.

Tab. 2. Enzymatische Hydrolyse von 2,3-Dimercapto-1-propanoltributyrat in Abhängigkeit von der Inkubationszeit. Die Testansätze enthielten 2,0 ml Dimethylsulfoxid, die Ablesung erfolgte bei $436 \mathrm{~nm}$.

Die relativen Angaben sind bezogen auf die Absorptionsdifferenzen bei $30 \mathrm{~min}$, die gleich $100 \%$ gesetzt wurden.

\begin{tabular}{lcccccc}
\hline \multicolumn{7}{c}{ Inkubationszeit bei $25^{\circ} \mathrm{C}$} \\
& $7,5 \mathrm{~min}$ & $15 \mathrm{~min}$ & $30 \mathrm{~min}$ \\
& $\overline{\mathrm{x}} \Delta \mathbf{A}$ & $\%$ & $\overline{\mathrm{x}} \Delta \mathbf{A}$ & $\%$ & $\overline{\mathrm{x}} \Delta \mathrm{A}$ & $\%$ \\
\hline "Lipase-Stand- & 0,277 & 19,0 & 0,667 & 45,8 & 1,460 & 100 \\
ard“452 U/1 & $\vdots:$ & & & & & \\
Serum Nr. 22 & 0,045 & 10,3 & 0,151 & 34,7 & 0,435 & 100 \\
Serum Nr. 29 & 0,143 & 12,1 & 0,403 & 34,1 & 1,181 & 100 \\
Serum Nr. 35 & 0,083 & 13,7 & 0,243 & 40,0 & 0,607 & 100 \\
Serum Nr. 64 & 0,054 & 10,2 & 0,189 & 35,6 & 0,532 & 100 \\
\hline Sollwert & & 25,0 & & 50,0 & & 100 \\
\hline
\end{tabular}

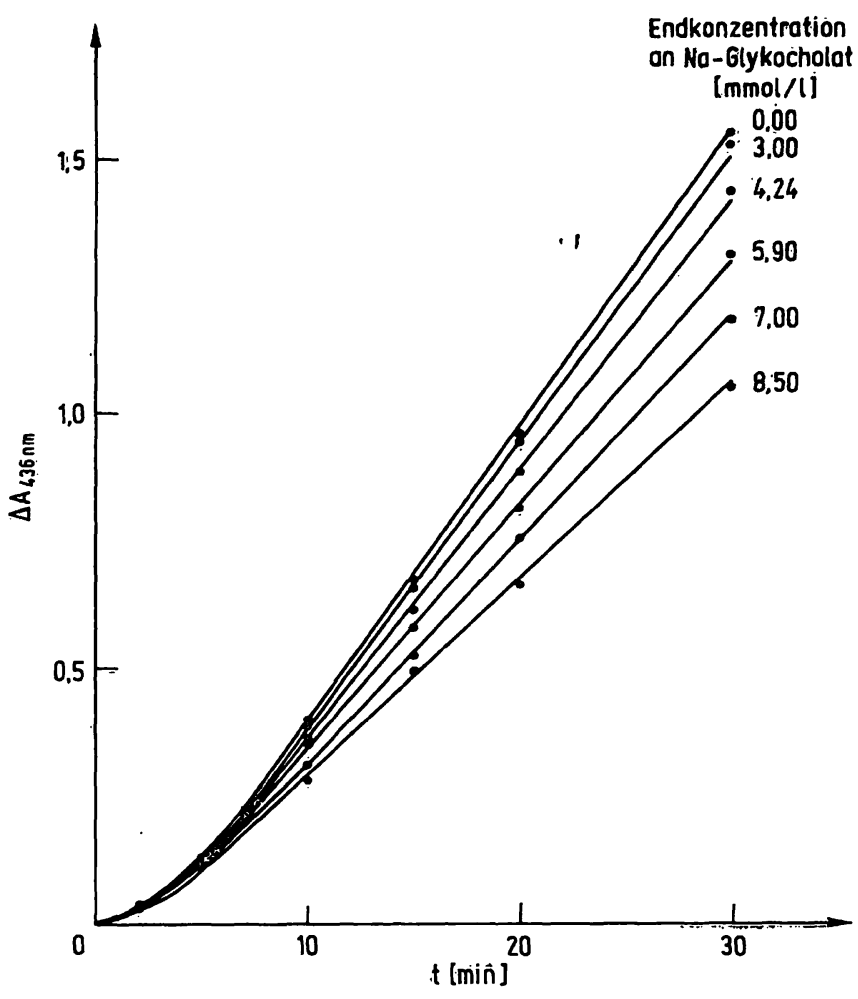

Abb. 3. Enzymatische Hydrolyse $\left(25^{\circ} \mathrm{C}\right)$ von 2,3-Dimercapto-1propanol-tributyrat in Abhängigkeit vion der Inkubationszeit und der Konzentration an Na-Glykocholat. Im Test:

Serum eines Patienten mit akuter Pankreatitis 2,0 ml Dimethylsulfoxid

Tab. 3. Enzymatische Hydrolyse von 2,3-Dimercapto-1-propanol-tributyrat in Abhängigkeit von der Inkubationszeit und der Konzentration an Na-Glykocholat, bezogen auf die nach 20 min gemessene Hydrolyse $(=100 \%)$. Serum eines Patienten mit akuter Pankreatitis und 2,0 ml Dimețylsulfoxid im Test.

Inkubationszeit bei $25^{\circ} \mathrm{C}$

Endkonz.

Na-

Glykocholat

\begin{tabular}{|c|c|c|c|c|c|c|c|}
\hline$(\mathrm{mmol} / \mathrm{l})$ & $2 \min$ & $5 \mathrm{~min}$ & $7 \mathrm{~min}$ & $10 \mathrm{~min}$ & $15 \min$ & $20 \mathrm{~min}$ & $30 \mathrm{~min}$ \\
\hline $\begin{array}{l}\text { ohne } \\
3,0 \\
4,24 \\
5,9 \\
7,0 \\
8,5\end{array}$ & $\begin{array}{l}4,1 \% \\
3,8 \% \\
4,3 \% \\
5,0 \% \\
5,7 \% \\
4,5 \%\end{array}$ & $\begin{array}{l}12,7 \% \\
13,3 \% \\
12,8 \% \\
15,5 \% \\
17,9 \% \\
18,7 \%\end{array}$ & $\begin{array}{l}22,9 \% \\
21,8 \% \\
24,0 \% \\
26,7 \% \\
27,3 \% \\
29,8 \%\end{array}$ & $\begin{array}{l}42,2 \% \\
40,2 \% \\
41,1 \% \\
43,1 \% \\
41,9 \% \\
42,2 \%\end{array}$ & $\begin{array}{l}71,2 \% \\
68,6 \% \\
70,2 \% \\
71,2 \% \\
69,5 \% \\
74,4 \%\end{array}$ & $\begin{array}{l}100 \% \\
100 \% \\
100 \% \\
100 \% \\
100 \% \\
100 \%\end{array}$ & $\begin{array}{l}162 \% \\
164 \% \\
164 \% \\
160 \% \\
157 \% \\
158 \%\end{array}$ \\
\hline Sollwert & $10 \%$ & $25 \%$ & $35 \%$ & $50 \%$ & $75 \%$ & $100 \%$ & $150 \%$ \\
\hline
\end{tabular}

\section{Enzymatische Hydrolyse von}

\section{2,3-Dimercapto-1-propanol-tributyrat in Abhängigkeit} von der eingesetzten Serumverdünnung

Wir untersuchten die Substrathydrolyse durch Serum in verschiedenen Verdünnungen mit physiologischer $\mathrm{NaCl}$ Lösung. Die Ergebnisse zeigen sowohl in Ansätżen mit Aceton als auch mit Dimethylsulfoxid keine Proportionalität zwischen Probevolumen im Test und gemessenen Absorptionsdifferenzen. Ansätze mit geringen Serumvolumina weisen einen deutlich zu niedrigen Sub- stratumsatz auf (Abb. 6). Nach Zusatz von Na-Glykocholat ergeben sich die in Abbildung 7 dargestellten komplizierten Zusammenhänge: Mit zunehmender Glykocholatkonzentration kômmt es bei Einsatz kleiner Probevolumina zu einer Zunahme des Substratumsatzes und es wird eine geradlinige Beziehung zwischen Serummenge und Farbentwicklung nachweisbar. Die gleichen Konzentrationen an Gallensäure führen jedoch in Testen mit mehr Serum bereits zu einer Hemmung des Substratumsatzes. So ist ès nicht möglich, eine Glykocholatkonzentration anzugeben; bei der bis zu 


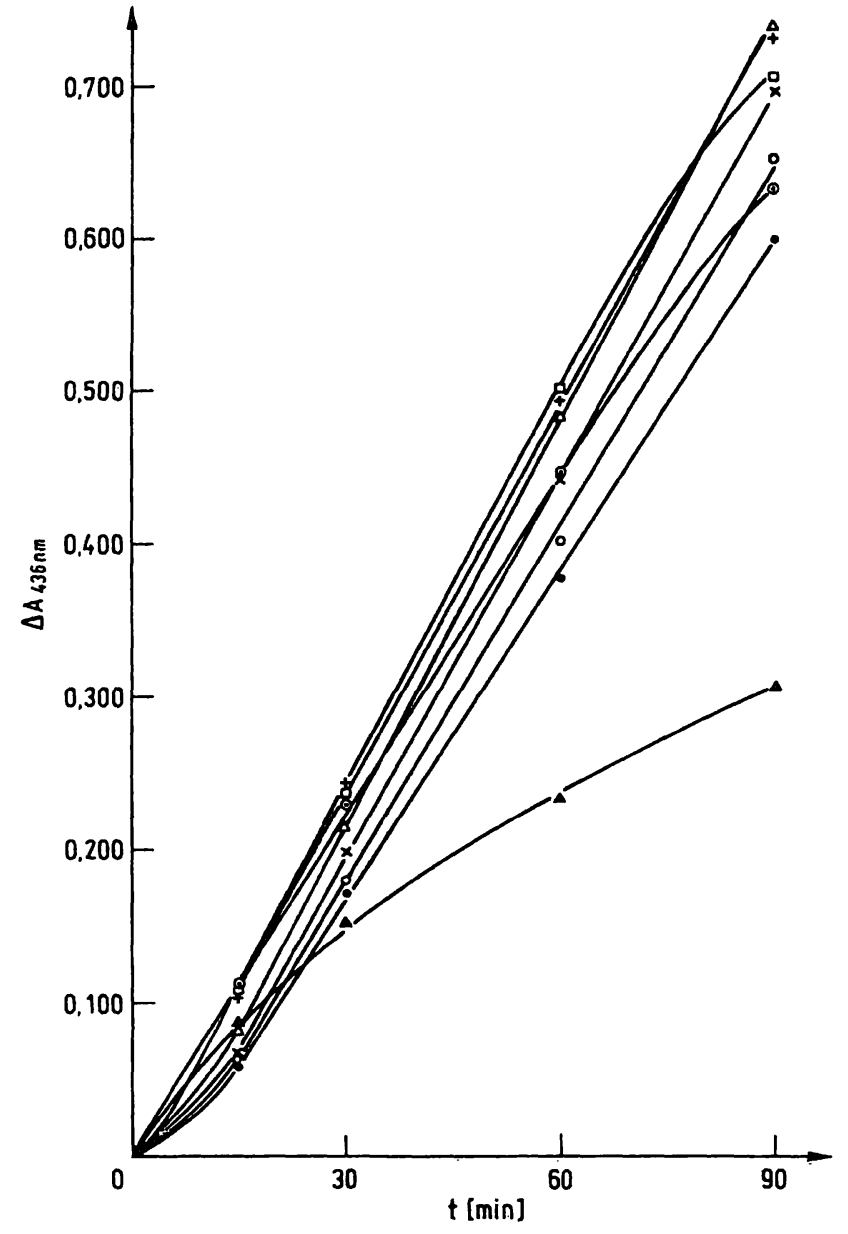

Abb. 4. Enzymatische Hydrolyse $\left(25^{\circ} \mathrm{C}\right)$ von 2,3-Dimercapto-1propanol-tributyrat in Abhängigkeit von der Inkubationszeit und der Konzentration an Na-Glykocholat.

Im Test:

Serum eines Gesunden

2,0 ml Dimethylsulfoxid

Endkonzentration an Na-Glykocholat (mmol/l):

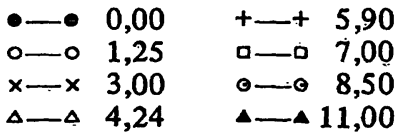

Tab. 4. Enzymatische Hydrolyse von 2,3-Dimercapto-1-propanoltributyrat in Abhängigkeit von der Inkubationszeit und der Konzentration an Na-Glykocholat, bezogen auf die nach 30 min gemessene Hydrolyse $(=100 \%)$.

Normalserum und 2,0 ml Dimethylsulfoxid im Test.

\begin{tabular}{lllll}
\hline \multicolumn{5}{c}{ Inkubationsżeit bei $25^{\circ} \mathrm{C}$} \\
$\begin{array}{l}\text { Endkonz. } \\
\text { Na-Glykocholat } \\
\text { (mmol/1) }\end{array}$ & $15 \mathrm{~min}$ & $30 \mathrm{~min}$ & $60 \mathrm{~min}$ & $90 \mathrm{~min}$ \\
\hline ohne & $36 \%$ & $100 \%$ & $221 \%$ & $352 \%$ \\
1,25 & $37 \%$ & $100 \%$ & $223 \%$ & $361 \%$ \\
3,0 & $36 \%$ & $100 \%$ & $223 \%$ & $353 \%$ \\
4,24 & $39 \%$ & $100 \%$ & $222 \%$ & $339 \%$ \\
5,9 & $44 \%$ & $100 \%$ & $203 \%$ & $302 \%$ \\
7,0 & $47 \%$ & $100 \%$ & $212 \%$ & $300 \%$ \\
8,5 & $50 \%$ & $100 \%$ & $195 \%$ & $276 \%$ \\
11,0 & $54 \%$ & $100 \%$ & $156 \%$ & $204 \%$ \\
\hline Sollwert & $50 \%$ & $100 \%$ & $200 \%$ & $300 \%$ \\
\hline
\end{tabular}

einem $\Delta \mathrm{A}$ von 1,0 eine Proportionalität besteht. $\mathrm{Ab}$ etwa $11,0 \mathrm{mmol} / 1 \mathrm{Gallensalz} \mathrm{wird} \mathrm{die} \mathrm{Lipase} \mathrm{bei} \mathrm{sämt-}$ lichen Serumverdünnungen deutlich gehemmt. Die Hydrolyse von 2,3-Dimercapto-1-propanol-tributyrat durch die verschiedenen Serumverdünungen in $\mathrm{Ab}$ hängigkeit von der Glykocholatkonzentration ist in

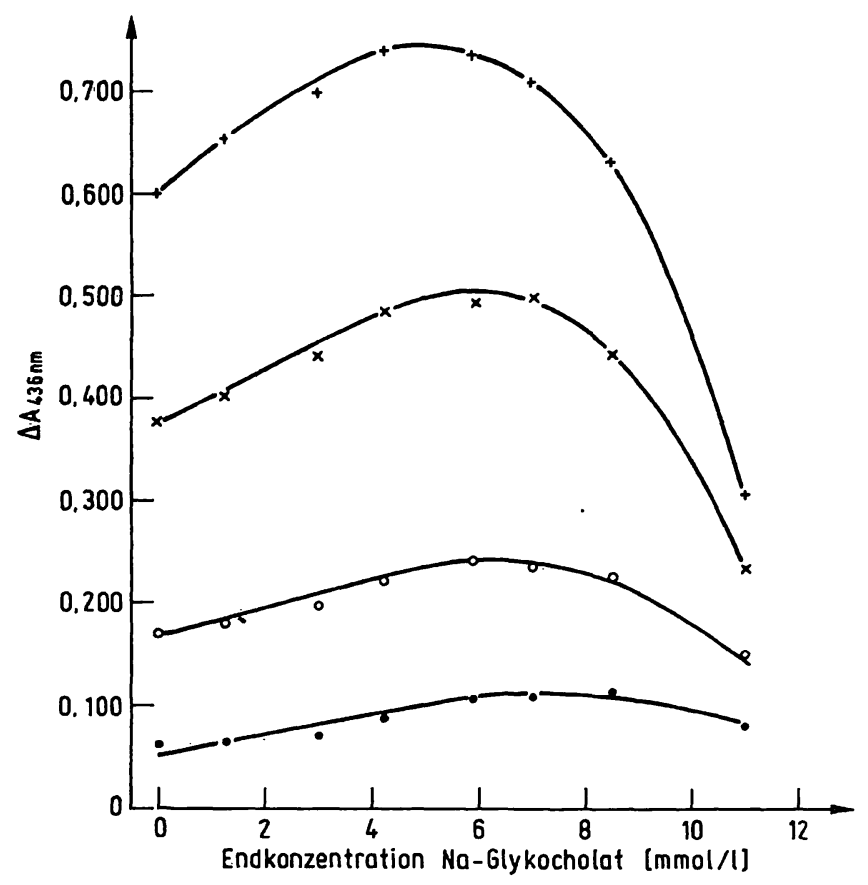

Abb. 5. Enzymatische Hydrolyse $\left(25^{\circ} \mathrm{C}\right)$ von 2,3-Dimercapto-1propanol-tributyrat in Abhängigkeit von der Inkubationszeit und der Konzentration an Na-Glykocholat. Im Test:

Serum eines Gesunden 2,0 ml Dimethylsulfoxid Inkubation ( $\mathrm{min})$ :

$$
\begin{aligned}
& -\longrightarrow 15 \\
& -\square \\
& x-\times 60 \\
& +\cdots+90
\end{aligned}
$$

Abbildung 8 nochmals gezeigt. Die optimale Glykocholatkonzentration verschiebt sich mit zunehmender Serummenge im Test zu geringeren Werten hin. Dementsprechend ist die Hemmwirkung höherer Glykocholatkonzentrationen bei hohen Serumverdünnungen weniger stark ausgeprägt. Wird das gleiche Serum anstelle von physiologischer $\mathrm{NaCl}$-Lösung mit inaktiviertem Sammelserum verdünnt, ergeben sich ganz andere Verhältnisse (Abb. 9). Unabhängig vom Lösungsmittel werden unter diesen Bedingungen mit abnehmender Serumverdünnung zu niedrige Substratumsätze gefunden. Auch hier versuchten wir, den Reaktionsablauf durch Zusatz von Na-Glykocholat zu verbessern. Niedrige Konzentationen an Gallensäuren steigerten die Farbintensität in allen Verdünnungen geringfugig, während bei Einsatz höherer Konzentrationen wiederum eine Hemmung beobachtet wurde (Abb. 10). Das Aus- 
maß von Aktivierung und Inhibition in Abhängigkeit von der Glykocholatkonzentration ist in Abbildung 11 wiederum zusammengefaßt.

Aus den Versuchen geht hervor, daß keine Testbedingungen gefunden werden konnten, die eine Analyse von Serumverdünnungen in dem von Kurooka et al. (1) angegebenen Bereich - bis zu Absorptionsdifferenzen von 1,0 - gestatten.

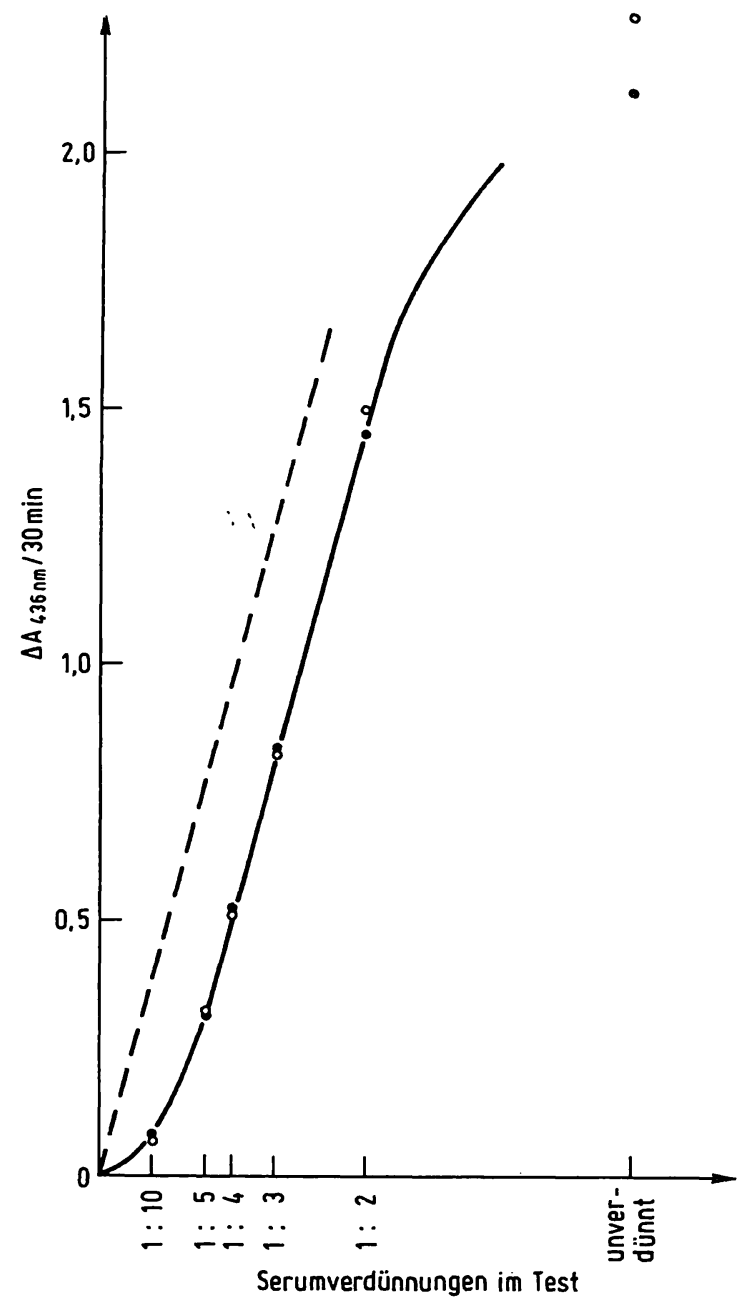

Abb. 6. Enzymatische Hydrolyse $\left(25^{\circ} \mathrm{C}\right)$ von 2,3-Dimercapto-1propanol-tributyrat in Abhängigkeit von der eingesetzten Serumverdünnung.

Im Test:

Serum eines Patienten mit akuter Pankreatitis Serumverdünnungen in physiologischer $\mathrm{NaCl}$-Lösung - - Ansätze mit Aceton

○_o Ansätze mit Dimethylsulfoxid

-..- theoretischer Verlauf bei konstanter Umsatzgeschwindigkeit

\section{Hemmung von Carboxylesterase aus Schweineleber durch Phenylmethylsulfonylfluorid}

Wie Kurooka et al. (1) bereits zeigten, wird 2,3-Dimercapto-1-propanol-tributyrat nicht nur von Lipasen, sondern auch durch Esterasen umgesetzt. Die Autoren versuchten, die esterolytischen Aktivitäten durch Zusatz von Phenylmethylsulfonylfluorid zum Testansatz zu hemmen. Wir prüften die Frage, ob diese Hemmung unter den gewähịlten Bedingungen vollständig ist.

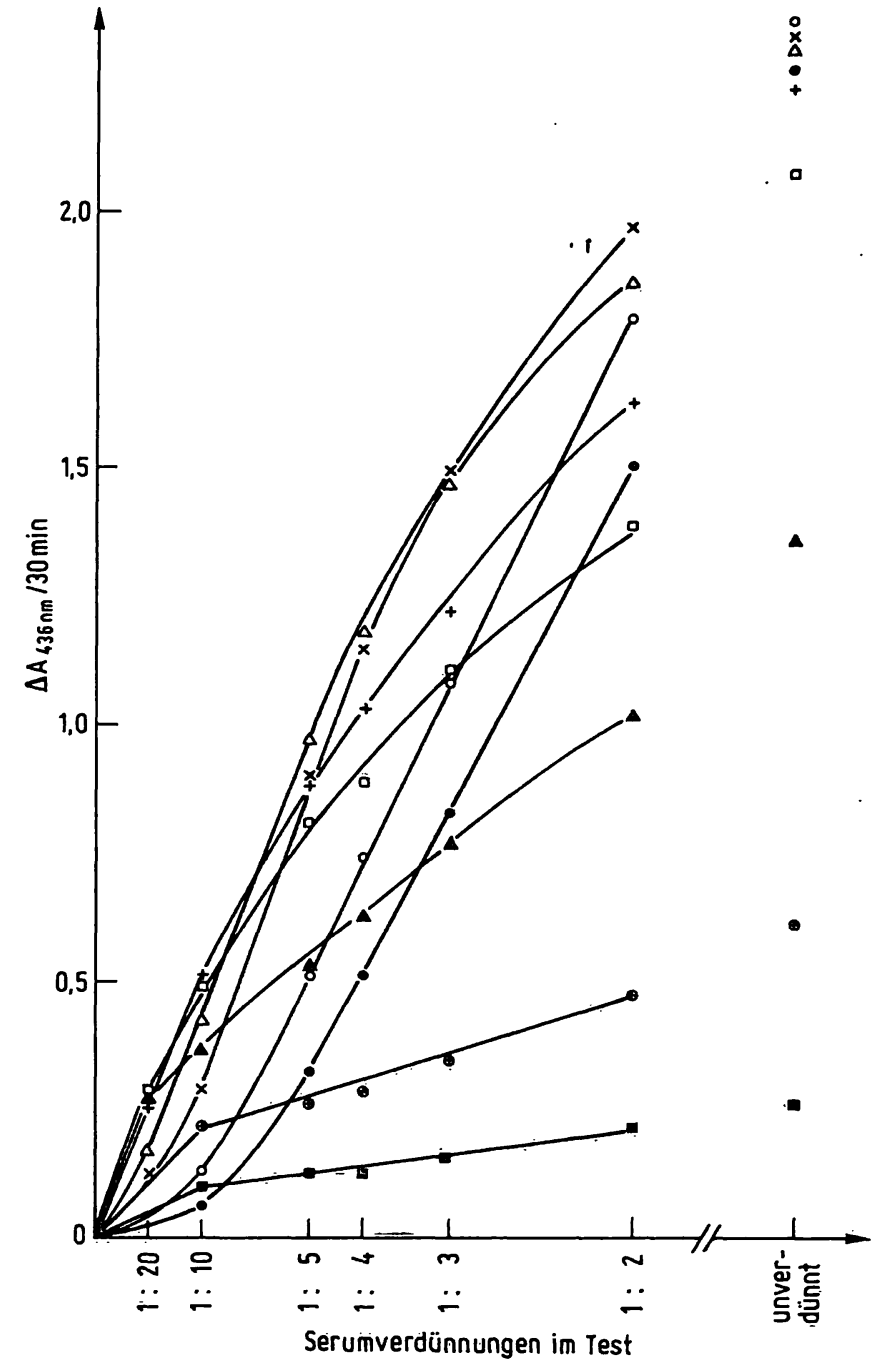

Abb. 7. Enzymatische Hydrolyse $\left(25^{\circ} \mathrm{C}\right)$ von 2,3-Dimercapto-1propanol-tributyrat in Abhängigkeit von der eingesetzten Serumverdünnung und der Konzentration an $\mathrm{Na}$-Glykocholat.

Im Test:

Serum eines Patienten mit akuter Pankreatitis Serumverdünnungen in physiologischer NaCl-Lösung 2,0 ml Dimethylsulfoxid

Endkonzentration an Na-Glykocholat (mmol/1):

$$
\begin{aligned}
& \longrightarrow 0,00 \quad \square-07,00 \\
& \circ \longrightarrow \quad 1,25 \quad \triangle-\triangle 11,00 \\
& x-x \quad 3,00 \quad-15,30 \\
& \Delta-\Delta \quad 4,24 \quad=19,10 \\
& +\ldots+5,90
\end{aligned}
$$

Setzt man Carboxylesterase aus Schweineleber in verschiedenen Verdünnungen in dèn Test ohne Phenylmethylsulfonylfluorid ein, so ergibt sich bis zu hohen katalytischen Aktivitäten ein geradliniger Zusammenhang zwischen eingesetzter Enzymmenge und Substratumsatz (Abb. 12). Im Gegensatz dazu zeigen Phenylmethylsulfonylfluorid-freie Ansätze mit Serum zwar höhere Absorptionsdifferenzen als Tests mit Inhibitor, jedoch einen unverändert nichtlinearen Kurvenverlauf. Inhibiert man verdünnte Esteraselösungen nach der Originalvorschrift mit Phenylmethylsulfonylfluorid in Gegenwart von Tris-HCl-Puffer und 5,5'-Dithio-bis(2-nitrobenzoat), so fällt auf, daß unabhängig davon, ob die Inhibitorkonzentration 1,0 oder $2,5 \mathrm{mmol} / 1$ beträgt 


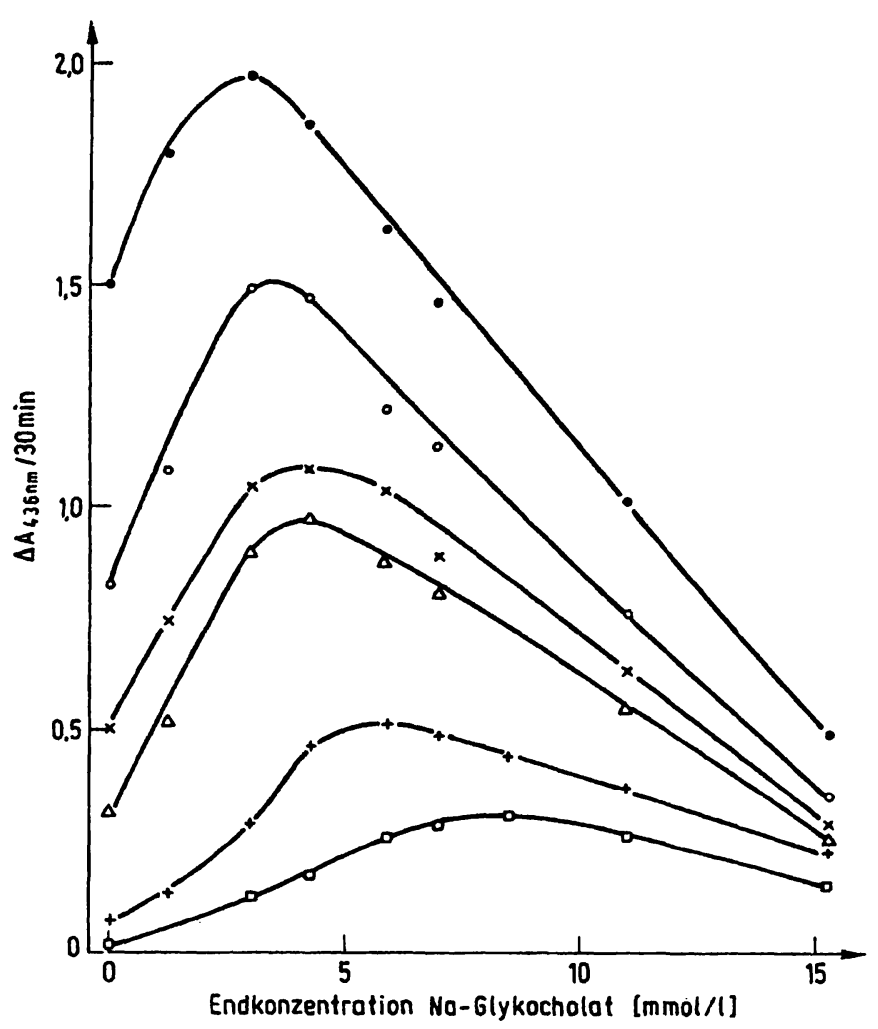

Abb. 8. Enzymatische Hydrolyse $\left(25^{\circ} \mathrm{C}\right)$ von 2,3-Dimercapto-1propanol-tributyrat in Abhängigkeit von der eingesetżen Serumverdünnung und der Konzentration an Na-Glykocholat.

Im Test:

Serum eines Patienten mit akuter Pankreatitis Serumverdünnungen in physiologischer $\mathrm{NaCl}$-Lösung 2,0 ml Dimethylsulfoxid

Endkonzentration an Na-Glykocholat s. Abszisse Verdünnungen des Serums:

$$
\begin{array}{ll}
\bullet \longrightarrow 1: 2 & \Delta-\Delta 1: 5 \\
\circ \longrightarrow 01: 3 & +\square+1: 10 \\
x \longrightarrow x 1: 4 & \text { - } 1: 20
\end{array}
$$

und ob 10 oder 30 Minuten vorinkubiert wird, die gleiche katalytische Restaktivität von etwa $14 \%$ beobachtet wird. Mischt man hingegen Esterase- und Phenylmethylsulfonylfluorid-Lösung allein und setzt das Farbreagens erst später zu, so ergeben sich die zu erwartenden Effekte: Verlängerung der Inkubationszeit und Erhöhung der Inhibitorkonzentration fựhren zu verstärkter Hemmung des Enzyms (s. Tab. 5). Weitere Versuche ergaben, daß bei vorheriger Mischung von Phenyl-

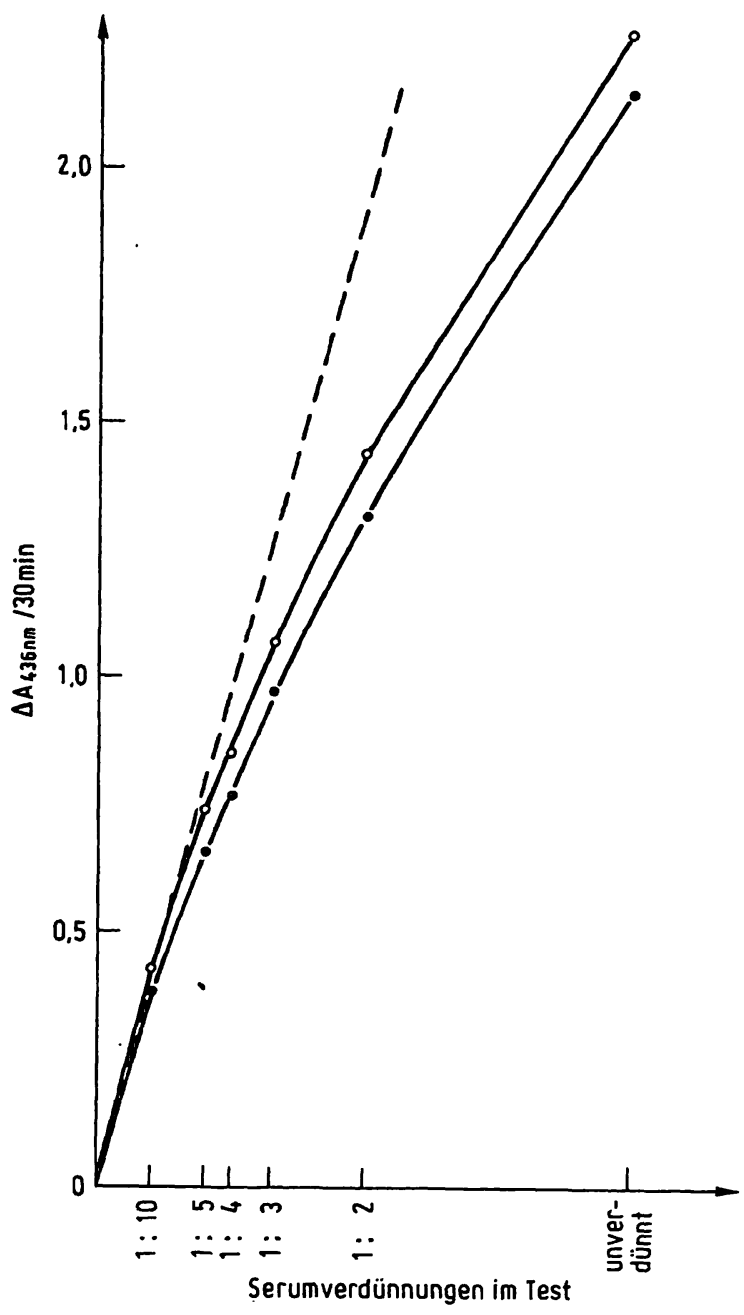

Abb. 9. Enzymatische Hydrolyse $\left(25^{\circ} \mathrm{C}\right)$ von 2,3-Dimercapto-1propanol-tributyrat in Abhängigkeit von der eingesetzten Serumverdünnung.

Im Test:

Serum eines Patienten mit akuter Pankreatitis Serumverdünnungen mit inaktiviertem Sammelserum

- - Ansätze mit Aceton

○-o Ansätze mit Dimethylsulfoxid

-..- theoretischer Verlauf bei konstanter Umsatzgeschwindigkeit

methylsulfonylfluorid-Lösung und Farbreagens-Gebrauchslösung der Hemmstoff seine Wirksamkeit zunehmend verliert. Somit ist nachgewiesen, daß beim Arbeiten nach der Originalvorschrift kein optimaler Hemmeffekt gewährleistet sein kann.

Tạb. 5. Hydrolyse von 2,3-Dimercapto-1-propanol-tributyrat durch Esterase aus Schweineleber (20 kU/l) in Abhängigkeit von der Konzentration an Phenylmethylsulfonylfluorid im Testansatz.

Die relativen Angaben beziehen sich auf die Aktivität in Ansätzen ohne Phenylmethylsulfonylfluorid gleich $100 \%$.

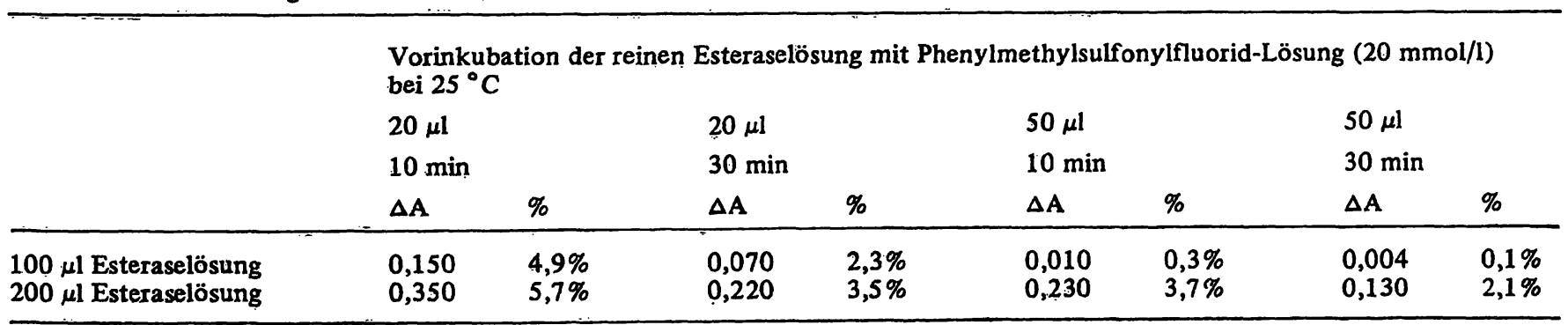




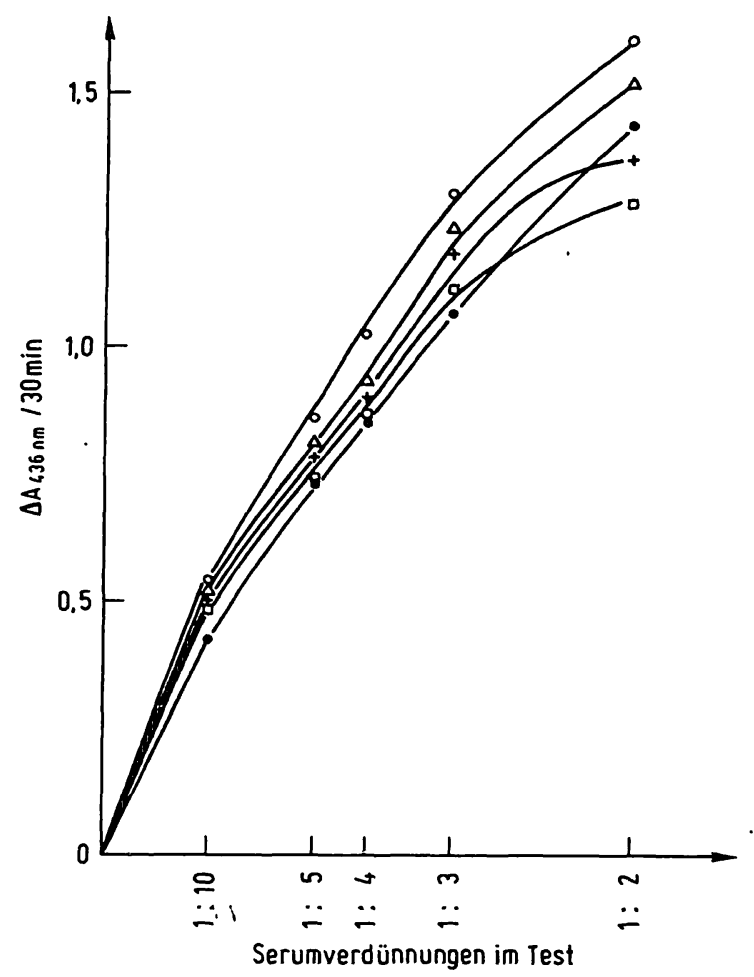

Abb. 10. Enzymatische Hydrolyse $\left(25^{\circ} \mathrm{C}\right)$ von 2,3-Dimercapto-1propanol-tributyrat in Abhängigkeit von der eingesetzten Serumverdünnung und der Konzentration an Na-Glykocholat.

Im Test:

Serum eines Patienten mit akuter Pankreatitis Serumverdünnung mit inaktiviertem Sammelserum 2,0 ml Dimethylsulfoxid

Endkonzentration an Na-Glykocholat (mmol/l):

$\bullet-0,00$

$\circ$ - 1,25

$\triangle-\triangle 4,24$

$++5,90$

口- 07,00

\section{Vergleichsuntersuchungen mit dem}

\section{kontinuierlichen titrimetrischen Test}

An 104 Seren von Patienten, die kein Heparin erhalten hatten, wurde der von Kurooka et al. (1) angegebene Test mit dem kontinuierlichen titrimetrischen Verfahren (2) verglichen. Wie eingangs beschrieben, ist eine Umrechnung von Ergebnissen der 2,3-Dimercapto-1propanol-tributyrat-Methode in U/1 nicht gerechtfertigt; daher wurden die bei $436 \mathrm{~nm}$ unter Verwendung von Dimethylsulfoxid ermittelten Absorptionsdifferenzen jeweils als Ordinatenwerte aufgetragen. Die in den $\mathrm{Ab}$ bildungen 13 und 14 dargestellten Ergebnisse zeigen signifikante Abweichungen nach dem Wilcoxon-Test $(P<0,0001)$. Die Gleichungen der Regressionsgeraden lauten: $y=0,0013 x-0,038$ und $y=0,0017 x-0,088$, die Korrelationskoeffizienten betragen $\mathrm{r}=0,768 \mathrm{bzw}$. $r=0,804$. Die ausgeprägten negativen Ordinatenabschnitte beruhen mit großer Wahrscheinlichkeit auf der sogenannten lag-Phase, die bei der Methode von Kurooka et al. (1) bereits beschrieben wurde (s. Abb. 1 und 2).

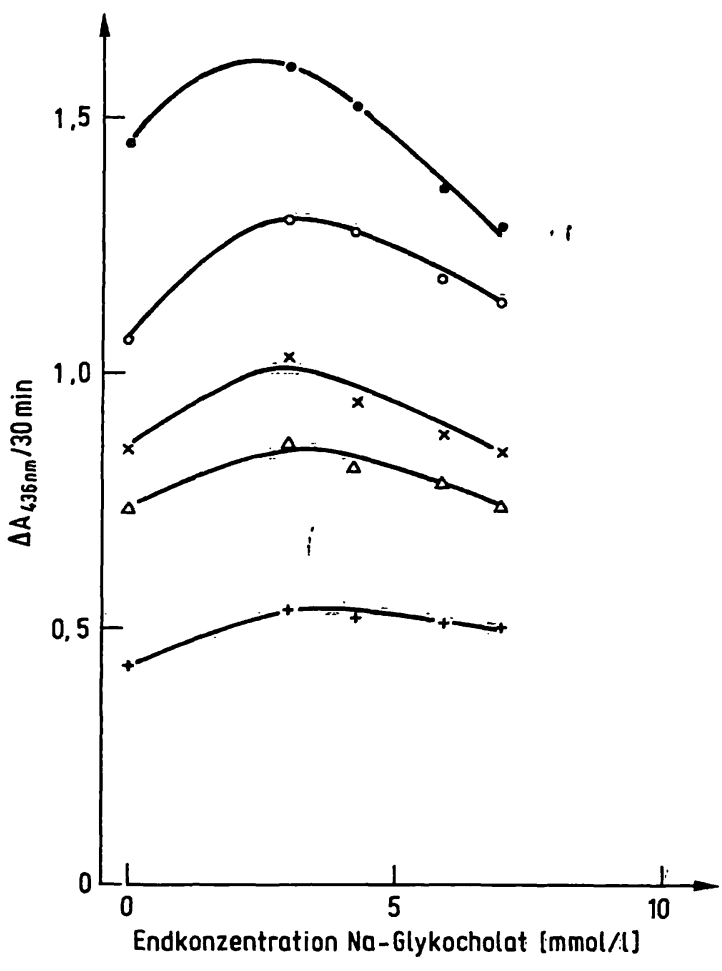

Abb. 11. Enżymatische Hydriolyse $\left(25^{\circ} \mathrm{C}\right)$ von 2,3-Dimercapto-1propanol-tributyrat in Abhängigkeit von der eingesetzten Serumverdünnung und der Konzentration an Na-Glykocholat.

Im Test:

Serum eines Patienten mit akuter Pankreatitis Serumverdünnungen mit inaktiviertem Sammelserum 2,0 ml Dimethylsulfoxid

Endkonzentration an Na-Glykocholat s. Abszisse

Verdünnungen des Serums:

$$
\begin{aligned}
& \bullet \longrightarrow 1: 2 \\
& \hdashline-01: 3 \\
& x-\times 1: 4 \\
& \Delta-\Delta 1: 5 \\
& +—+1: 10
\end{aligned}
$$

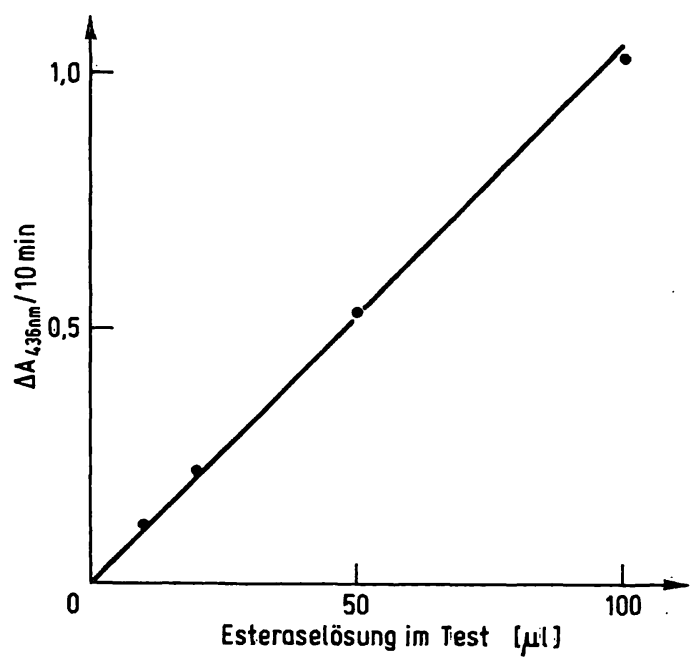

Abb. 12. Enzymatische Hydrolyse $\left(25^{\circ} \mathrm{C}\right)$ von 2,3-Dimercapto-1propanol-tributyrat durch Esterase aus Schweineleber $(20 \mathrm{kU} / 1)$

Im Test:

2,0 ml Dimethylsulfoxid

Inkubation $10 \mathrm{~min}$ bei $25^{\circ} \mathrm{C}$. . . 


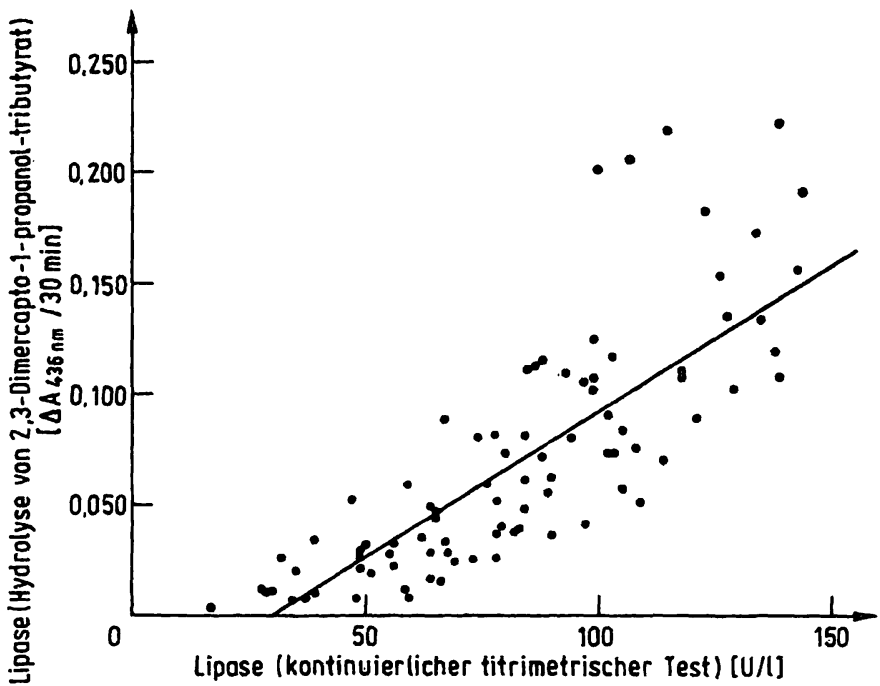

Abb. 13. Vergleich des von Kurooka et al. beschriebenen Verfahrens (Hydrolyse von 2,3-Dimercapto-1-propanoltributyrat (Testpackung ,Marupi“)) mit dem kontinuierlichen titrimetrischen Verfahren an 89 Seren mit einer katalytischen Aktivität an Lipase bis zu $150 \mathrm{U} / 1$.

$y=0,0013 x-0,038$

$\mathrm{r}=0,768$

Verwendung selbst angesetzter Substratlösungen

Hydrolyse von 2,3-Dimercapto-1-propanol-tributyrat in Abhängigkeit von der Konzentration an Na-Glykocholat und Na-Dodecylsulfat

Da ungeklärt ist, welche Rolle oberflächenaktive Substanzen in dem von Kurooka et al. (1) angegebenen Testsystem spielen, führten wir Versuche mit selbst angesetzten Substratlösungen ohne Na-Dodecylsulfat durch. Es zeigt sich (Abb. 15), daß bei Ansätzen ohne NaDodecylsulfat keine lag-Phase beobachtet wird. Ohne Gallensäuren im Test verläuft die enzymatische $\mathrm{Hy}$ drolyse von 2,3-Dimercapto-1-propanol-tributyrat bei der eingesetzten Lipase mindestens 40 Minuten geradlinig. Bei Zusatz von $0,64 \mathrm{mmol} / 1 \mathrm{Na}$-Glykocholat kommt es anfangs zu einer geringen Aktivierung; der lineare Reaktionsablauf dauert jedoch nur etwa 15 Minuten, danach ergibt sich ein zunehmend gekrümmter Kurvenverlauf. Mit 5,9 mmol/1 Na-Glykocholat ist der Effekt noch stärker ausgeprägt. Die mit Na-Dodecylsulfat-haltigem Substrat gefundenen Werte mit lagPhase sind zum Vergleich eingetragen. Verschiedene andere Seren zeigten ein ähnliches Verhalten, allerdings war der lineare Verlauf jeweils unterschiedlich lange nachweisbar.

Abb. 15. Enzymatische Hydrolyse $\left(25^{\circ} \mathrm{C}\right)$ von 2,3-Dimercapto-1propanol-tributyrat in Abhängigkeit von der Inkubationszeit und der Konzentration an Na-Glykocholat.

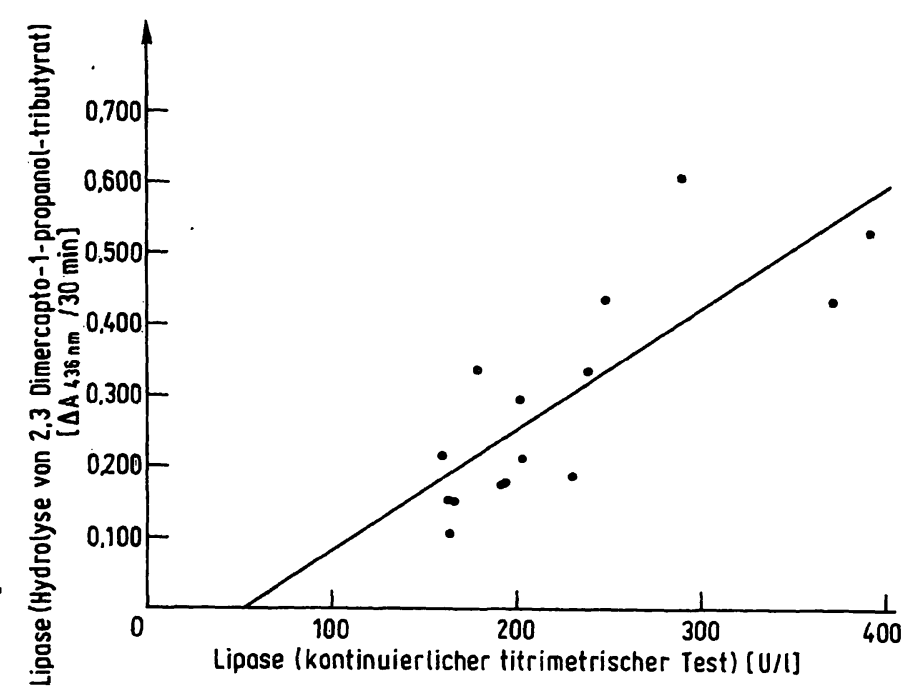

Abb. 14. Vergleich des von Kurooka et al. beschriebenen Verfahrens (Hydrolyse von 2,3-Dimercapto-1-propanoltributyrat (Testpackung „Marupi“)) mit dem kontinuierlichen titrimetrischen Verfahren an 15 Seren mit mäßig erhöhter Lipase.

$y=0,0017 x-0,088$ $r=0,804$

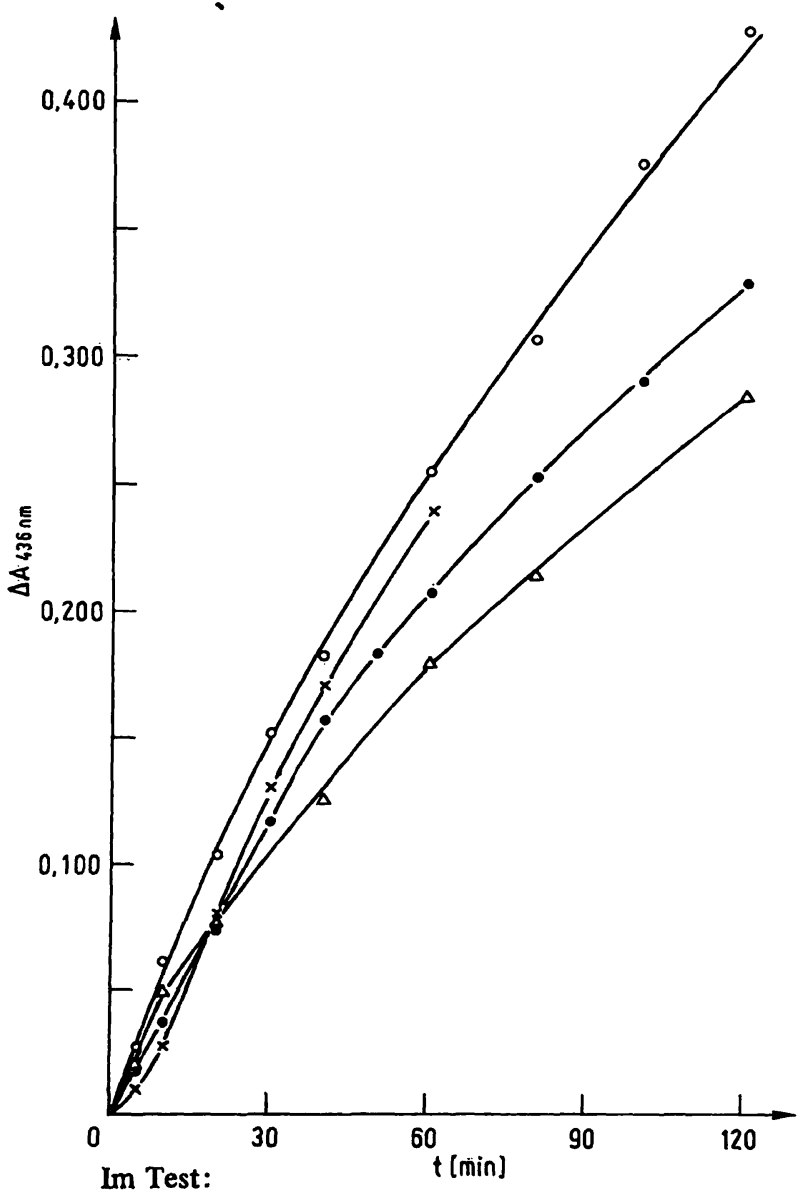

Serum eines Gesunden 2,0 ml Dimethylsulfoxid

\begin{tabular}{lll}
\hline & $\begin{array}{l}\text { Na-Glykocholat } \\
(\mathrm{mmol} / \mathrm{l})\end{array}$ & $\begin{array}{l}\text { Na-Dodecylsulfat } \\
(\mathrm{mmol} / \mathrm{l})\end{array}$ \\
\hline$\square$ & $-\overline{6}$ & -- \\
$\mathrm{0}-\mathrm{0}$ & 0,64 & -- \\
$\Delta-\mathrm{x}$ & 0,64 & 1,7 \\
\hline
\end{tabular}


Hydrolyse von 2,3-Dimercapto-1-propanol-tributyrat in Abhängigkeit von der Serumverdünnung sowie von den Konzentrationen an Na-Glykocholat und Na-Dodecylsulfat

Wir prüften weiterhin den Einfluß von Na-Dodecylsulfat auf die Farbentwicklung bei Einsatz verdünnter Seren in den Test. Verwendet man physiologische $\mathrm{NaCl}$-Lösung als Verdünnungsmittel (Abb. 16), so ergeben sich bei einer Probe mit hoher Lipaseaktivität in Abwesenheit von Na-Dodecylsulfat nur sehr geringe Absorptionsdifferenzen, jedoch besteht eine geradlinige Beziehung

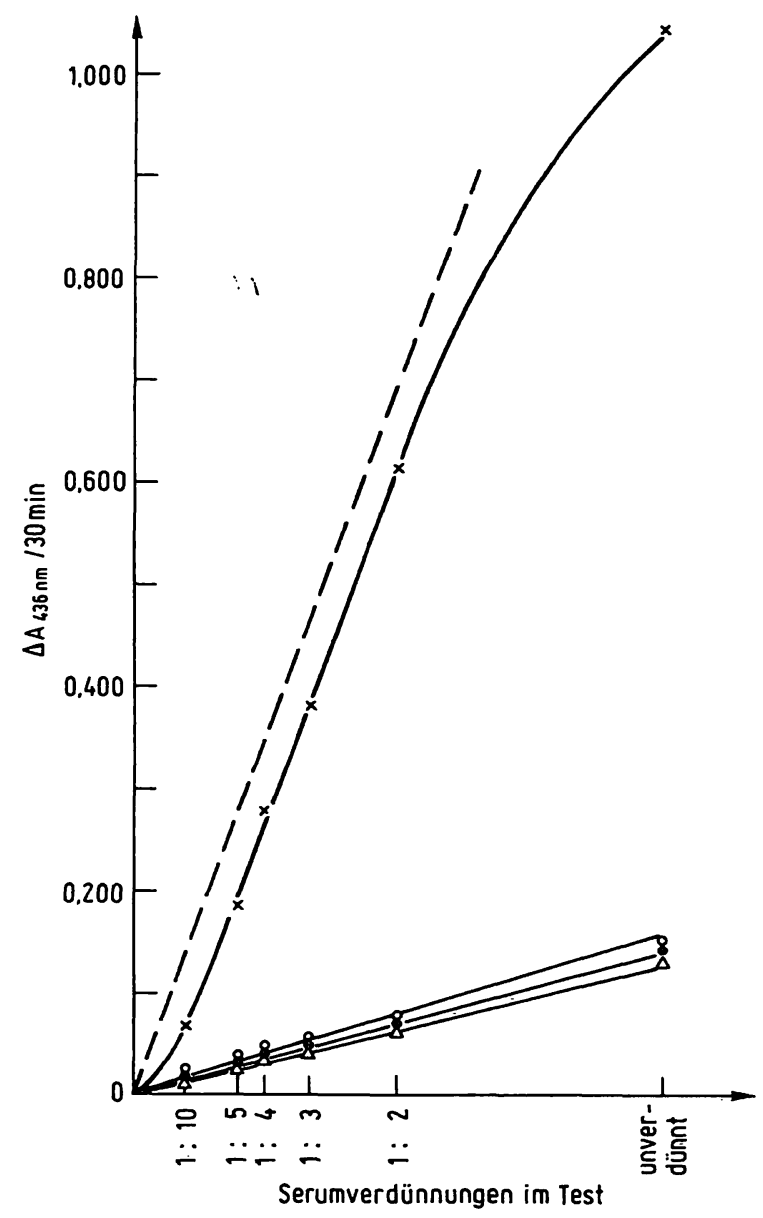

Abb. 16. Enzymatische Hydrolyse $\left(25^{\circ} \mathrm{C}\right)$ von 2,3-Dimercapto1-propanol-tributyrat in Abhängigkeit von der eingesetzten Serumverdünnung.

Im Test:

Serum eines Patienten mit akuter Pankreatitis Serumverdünnungen in physiologischer NaCl-Lösung 2,0 ml Dimethylsulfoxid

\begin{tabular}{|c|c|c|}
\hline & $\begin{array}{l}\text { Na-Glykocholat } \\
(\mathrm{mmol} / \mathrm{l})\end{array}$ & $\begin{array}{l}\text { Na-Dodecylsulfat } \\
(\mathrm{mmol} / \mathrm{l})\end{array}$ \\
\hline •- & -- & -- \\
\hline 0—o & 0,64 & -- \\
\hline$x-x$ & 0,64 & 1,7 \\
\hline$-\cdots$ & \multicolumn{2}{|c|}{$\begin{array}{l}\text { theoretischer Verlauf bei konstanter } \\
\text { Umsatzgeschwindigkeit }\end{array}$} \\
\hline$\Delta \_\Delta$ & 5,9 & -- \\
\hline
\end{tabular}

zwischen eingesetztem Probèvolumen und Meßsignal. Zusatz von Na-Dodecylsulfat führt zu einer vielfach höheren Farbintensität mit der bereits beschriebenen Abweichung von der Proportionalität. Erfolgt die Verdünnung der Probe dagegen mit inaktiviertem Sammelserum, so zeigt sich in Na-Dodecylsulfat-freien A'rlsätzen überhaupt kein Zusammenhang zwischen eingesetzter Enzymmenge und Meßsignal; die Farbentwicklung bleibt in allen Verdünnungen annähernd konstant. NaDodecylsulfat im Test ergibt wieder eine starke $\mathrm{Zu}$ nahme der Absorptionsdifferenzen, wobei mit dem verwendeten Serum eine geradlinige Abhängigkeit vom Probevolumen bis zu einem $\Delta \mathrm{A} / 30 \mathrm{~min}$ von etwa 0,600 erzielt wird (Abb. 17).

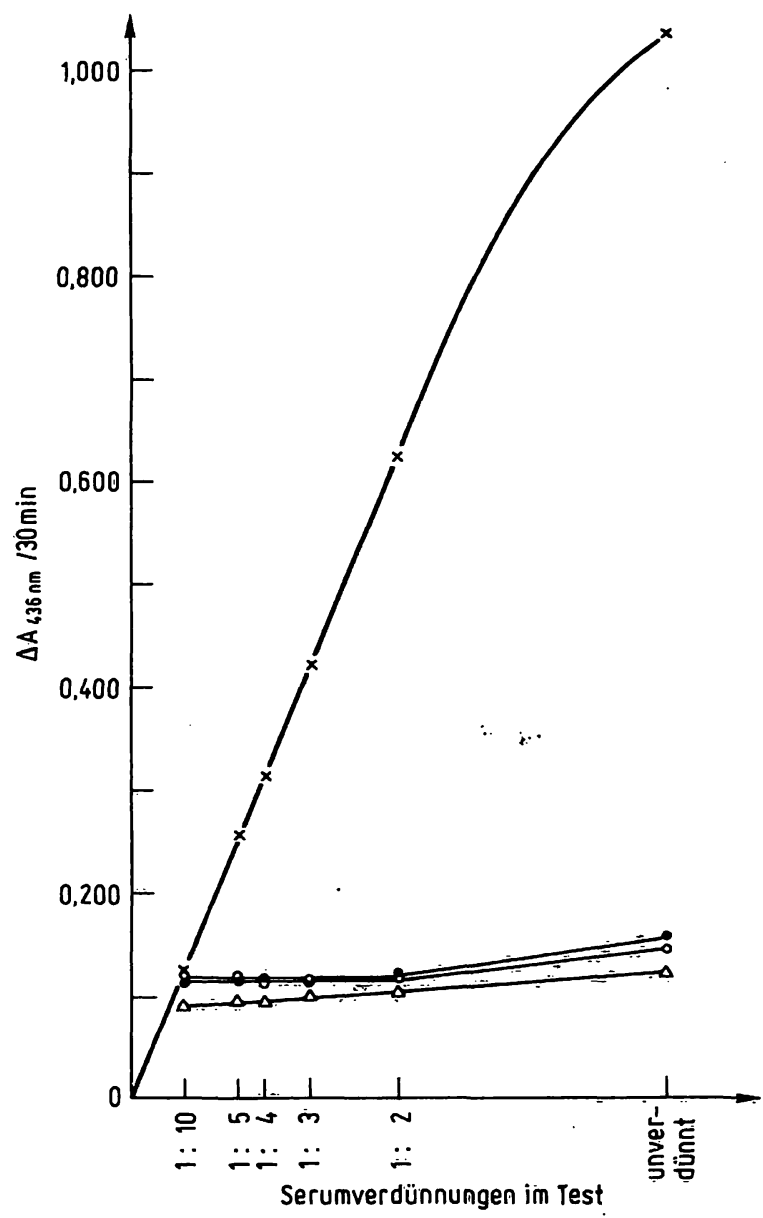

Abb. 17. Enzymatische Hydrolyse $\left(25^{\circ} \mathrm{C}\right)$ von 2,3-Dimercapto1-propanol-tributyrat in Abhängigkeit von der eingesetzten Serumverdünnung.

Im Test:

Serum eines Patienten mit akuter Pankreatitis Serumverdünnungen mit inaktiviertem Sammelserum 2,0 ml Dimethylsulfoxid

\begin{tabular}{|c|c|c|}
\hline & $\begin{array}{l}\text { Na-Glykocholat } \\
(\mathrm{mmol} / \mathrm{l})\end{array}$ & $\begin{array}{l}\text { Na-Dodecylsulfat } \\
\text { (mmol/l) }\end{array}$ \\
\hline$\bullet$ & -- & -- \\
\hline $0-0$ & 0,64 & -- \\
\hline$x-x$ & 0,64 & 1,7 \\
\hline$\Delta-\Delta$ & 5,90 & -- \\
\hline
\end{tabular}




\section{Walter de Gruyter Berlin-New York}

\section{K. Fotherby S. B. Pal (Editors)}

\section{K. Agarwal} (Editor)

\section{Hormones in Normal and Abnormal Human Tissues}

\section{Volume 1}

1980. $17 \mathrm{~cm} \times 24 \mathrm{~cm}$. XIV, 658 pages with figures and tables. Hardcover. DM 145,-; approx. US $\$ 72.50$ ISBN 3110080311

\section{Volume 2}

1981. $17 \mathrm{~cm} \times 24 \mathrm{~cm}$. XII, 552 pages with figures and tables. Hardcover. DM 135,-; approx. US $\$ 67.50$ ISBN 3110085410

\section{Volume 3}

1982. $17 \mathrm{~cm} \times 24 \mathrm{~cm}$. Approx. 500 pages with figures and tables. Hardcover. Approx. DM 120,-; approx. US $\$ 60.00$ ISBN 3110086166

Hormones in Normal and Abnormal Human Tissues is a threevolume monograph dealing with the circulating levels, the pathological and therapeutic conditions and the factors controlling the secretion of non-polypeptide, protein and steroid hormones.

An attempt has been made to place emphasis on the concentration of the various hormones in tissues; where they are produced and where they might localize and produce an effect, and how these levels are modified under various circumstances.

\section{Hormone Antagonists}

$1982.17 \mathrm{~cm} \times 24 \mathrm{~cm}$. IX, 734 pages. Numerous illustrations. Hardcover. DM 180,-; approx. US $\$ 90.00$ ISBN 3110086131

This book groups together under one single cover antagonists for those hormones where antagonism has been documented specifically and with a certain degree of certitude. The major emphasis has been delineation of anti-hormone activity at the level of the hormone receptor but other aspects, such as antibody mediated antagonism and inhibition of synthesis, have been included to indicate other possible levels of inhibition of hormone activity. Clinical aspects, too, have been covered where they were documented with certitude.

It is felt that the book represents a major new reference source for years to come. Scientists, medical academicians, and advanced graduate students may use the book as a departing point for further pursuit of their own field. Involved research workers will find the volume of much interest since it provides data not published elsewhere. The book may also be used as a text volume to indicate the diversity and the wealth of information on the subject of hormone antagonism both in the basic research and in clinical medicine. Photo-offset method of publication assures expediency before specialized articles obsolete novelty. 


\section{Walter de Gruyter Berlin-New York}

\section{H. Kleinkauf H. v. Döhren (Editors)}

F. Hucho

(Editor)

\section{Peptide Antibiotics Biosynthesis and Functions Enzymatic Formation of Bioactive
Peptides and Related Compounds}

$1982.17 \mathrm{~cm} \times 24 \mathrm{~cm}$. XII, 479 pages. Numerous illustrations. Hardcover. DM 190,-; approx. US \$95.00 ISBN 3110084848

The book represents the current state of work in biosynthesis and functions of bioactive peptides, especially peptide antibiotics. In 40 contributions all aspects of the enzymatic formation of peptides are presented, including pathways, fermentation and production of peptides and synthetases, multienzyme systems and peptide bond forming reactions, modification and possible functions of peptide antibiotics within their producer organisms. The compounds discussed are gramicidin S, gramicidin, tyrocidine, bacitracin, polymyxins, penicillins and cephalosporins, actinomycin, mycobacillin, ergot peptides, edeine, leupeptin, carnosin, folyl-poly- $y$-glutamates, amatoxins, and the poly- $y-D$ glutamyl capsule.

\section{Neuroreceptors}

\section{Proceedings of the Symposium Berlin (West), September 28-29, 1981}

$1982.17 \mathrm{~cm} \times 24 \mathrm{~cm}$. XIV, 367 pages. Numerous illustrations. Hardcover. DM 150,-; approx. US \$75.00 ISBN 311008855X

This volume contains reviews and original data on some of the neural receptors, which are at present the focus of interest. They were presented at a meeting held in Berlin on September 28 and 29, 1981. More than half of the volume deals with the nicotinic acetylcholine receptor, not merely because we consider this receptor the most interesting or the most important molecule of its kind, but also because we feel that its biochemical investigation is, for technical reasons, at present fairly advanced.

Whereas some of the other receptors presented here have not yet gone farther than the stage of hypothesis, others are already visible at least on autoradiograms, after radioactive labelling. The basic questions and the techniques for answering these appear to be very similar so that any exchance of ideas and experiences appears to be useful. 
Hydrolyse von 2,3-Dimercapto-1-propanol-tributyrat durch verschiedene Seren bei unterschiedlichen Testbedingungen

Wie die in Tabelle 6 angegebenen Daten zeigen, besteht bei den gefundenen Absorptionsdifferenzen keinerlei Proportionalität zu den im kontinuierlichen titrimetrischen Test gemessenen katalytischen Aktivitäten von Lipase. Ohne Na-Dodecylsulfat im Ansatz führt inaktiviertes Sammelserum zu einer deutlichen Farbentwicklung, Normalserum und Serum von Pankreatitispatienten ergeben kaum Unterschiede in den Meßwerten. Nach Zusatz von Phenylmethylsulfonylfluorid und EDTA (4) werden die Absorptionen zwar deutlich geringer, wesentliche Differenzen zwischen Seren mit verschiedenen Lipaseaktivitäten ergeben sich jedoch nicht. Erst der Zusatz von Na-Dodecylsulfat bewirkt das Verschwinden der „Aktivität" von inaktiviertem Sammelserum und andererseits deutliche Unterschiede zwischen den eingesetzten Proben.

\section{Versuche zur Entwicklung eines kon tinuierlichen Tests}

$\mathrm{Da}$ die beim bisher verwendeten Zweipunkttest aufgetretenen Probleme u.a. auf dem Vorhandensein einer lag-Phase beruhen, versuchten wir, die Hydrolyse von 2,3-Dimercapto-1-propanol-tributyrat kontinuierlich photometrisch zu verfolgen, um so eine Auswertung des späteren linearen Reaktionsablaufs zu ermöglichen. Mit Hilfe von Na-Glykocholat in einer Konzentration von $1,5 \mathrm{mmol} / 1$ und von $0,1 \mathrm{~mol} / 1$ Tris-HCl-Puffer, $\mathrm{pH} 8,8$ ließen sich Emulsionen mit 2,3-Dimercapto-1-propanoltributyrat durch Homogenisieren im Starmix analog zur Substratemulsion für den kontinuierlichen titrimetrischen Test mit Triolein (2) herstellen. Mischt man eine Substratemulsion von 2,42 mmol/1 2,3-Dimercapto-1- propanol-tributyrat und Farbreagens-Gebrauchslösung, so ergibt sich eine stark getrübte Lösung; die gemessenen Änderungen der Farbintensität nach Zugabe von Serum, das mit Phenylmethylsulfonylfluorid vorinkubiert wurde, steht in keiner Beziehung zur Lipaseaktivität der eingesetzten Probe. Wird dem Ansatz außerdem Na-Dodecylsulfat in einer Endkonzentration von $1,7 \mathrm{mmol} / \mathrm{l}$ (1) zugefügt, ergeben sich wie bei dem Zweipunktverfahren eine lag-Phase und stark erhöhte Farbintensitäten. Da sich auch ohne Serum im Test sehr starke, nicht lineare Absorptionszunahmen mit der Zeit zeigten, war eine Messung der Hydrolyse von 2,3-Dimercapto-1-propanol-tributyrat mit diesem Verfahren nicht möglich.

Ansätze mit konzentrierteren 2,3-Dimercapto-1propanol-tributyrat-Emulsionen sind wegen ihrer starken Trübung nicht für die photometrische Messung geeignet.

\section{Kon tinuierlicher titrimetrischer Test}

\section{Zur Spezifität des Verfahrens mit}

\section{2,3-Dimercapto-1-propanol-tributyrat als Substrat}

Ester von Glycerin bzw. 2,3-Dimercapto-1-propanol mit kurzkettigen Fettsäuren werden sowohl von Lipase als auch von Esterasen hydrolysiert. Die spezifische Aktivität von Carboxylesterase aus Schweineleber gegenüber Tributyrin beträgt $31500 \mathrm{U} / \mathrm{g}$, diejenige gegenüber 2,3-Dimercapto-1-propanol-tributyrat $19500 \mathrm{U} / \mathrm{g}(5)$. Um die Spezifität der von Kurooka et al. (1) beschriebenen Methode für Lipase zu erhöhen, wird Phenylmethylsulfonylfluorid als Esterase-Hemmstoff angewandt. Wir prüften die Wirkung des Inhibitors in einem kontinuierlichen titrimetrischen Test mit Tween 20 als Substrat, das von Esterasen, nicht aber von Lipase umgesetzt wird (2). Eine 25 Minuten dauernde Vorinkuba-

Tab. 6. Hydrolyse von 2,3-Dimercapto-1-propanol-tributyrat durch verschiedene Seren. Im Test: 2,0 ml Dimethylsulfoxid, kein Na-Glykocholat.

\begin{tabular}{|c|c|c|c|c|}
\hline & Ohne Hemmstoff & $+20 \mathrm{mmol} / 1$ Phen & thylsulfonylfluorid & $+20 \mathrm{mmol} / \mathrm{l}$ \\
\hline & $\begin{array}{l}\text { ohne } \\
\text { Na-Dodecylsulfat }\end{array}$ & $\begin{array}{l}\text { ohne } \\
\text { Na-Dodecylsulfat }\end{array}$ & $\begin{array}{l}\text { mit } \\
\text { Na-Dodecylsulfat }\end{array}$ & $\begin{array}{l}\text { ohne } \\
\text { Na-Dodecylsulfat }\end{array}$ \\
\hline .. & $\Delta \mathrm{A} / 30 \min { }^{\circ}$ & $\Delta \mathrm{A} / 30 \mathrm{~min}$ & $\Delta A / 30 \min$ & $\Delta \mathrm{A} / 30 \mathrm{~min}$ \\
\hline $\begin{array}{l}\text { Inaktiviertes Sammelserum } \\
0 \mathrm{U} / 1\end{array}$ & 0,185 & 0,114 & 0,000 & 0,108 \\
\hline $\begin{array}{l}\text { Normalserum } \\
130 \mathrm{U} / 1\end{array}$ & 0,566 & 0,104 & 0,148 & 0,107 \\
\hline $\begin{array}{l}\text { Serum P } 1 \\
710 \mathrm{U} / 1\end{array}$ & 0,520 & 0,143 & 0,971 & 0,142 \\
\hline $\begin{array}{l}\text { Serum P } 2 \\
2080 \mathrm{U} / 1\end{array}$ & 0,485 & 0,130 & 2,322 & 0,104 \\
\hline $\begin{array}{l}\text { „Postheparinserum" } \\
280 \mathrm{U} / \mathrm{i}\end{array}$ & 0,738 & 0,240 & 0,166 & 0,200 \\
\hline
\end{tabular}


tion von Serum von Pankreatitispatienten mit Phenylmethylsulfonylfluorid in einer Endkonzentration von $3,3 \mathrm{mmol} / 1$ bei $25^{\circ} \mathrm{C}$ führt nicht zu einer vollständigen Inhibition der Esterasen in der von uns verwendeten Probe. Erst nach einer 50 Minuten langen Reaktionszeit unter diesen Bedingungen ist keine Aktivität gegen Tween 20 mehr nachweisbar (Abb. 18). Die von Kurooka et al. (1) vorgeschlagene 5 Minuten dauernde Einwirkung (bei $30^{\circ} \mathrm{C}$ ) von Phenylmethylsulfonylfluorid auf die Probe in Gegenwart von 5,5'-Dithio-bis(2-nitrobenzoat), das Phenylmethylsulfonylfluorid langsam in seiner Wirkung beeinträchtigt (s.o.), genügt mithin keinesfalls, um die esterolytischen Enzyme des Serums vollständig unwirksam zu machen. Das als Hemmstoff der Arylesterase verwendete EDTA (4) ergab unter gleichen Testbedingungen in einer Endkonzentration von $1,0 \mathrm{mmol} / \mathrm{l} \mathrm{keine}$ Änderung der Hydrolysegeschwindigkeit von Tween 20 durch Serum von Pankreatitispatienten.

In weiteren Versuchen wurde geprüft, ob Phenylmethylsulfonylfluorid die Pankreaslipase beeinflußt. Es zeigte

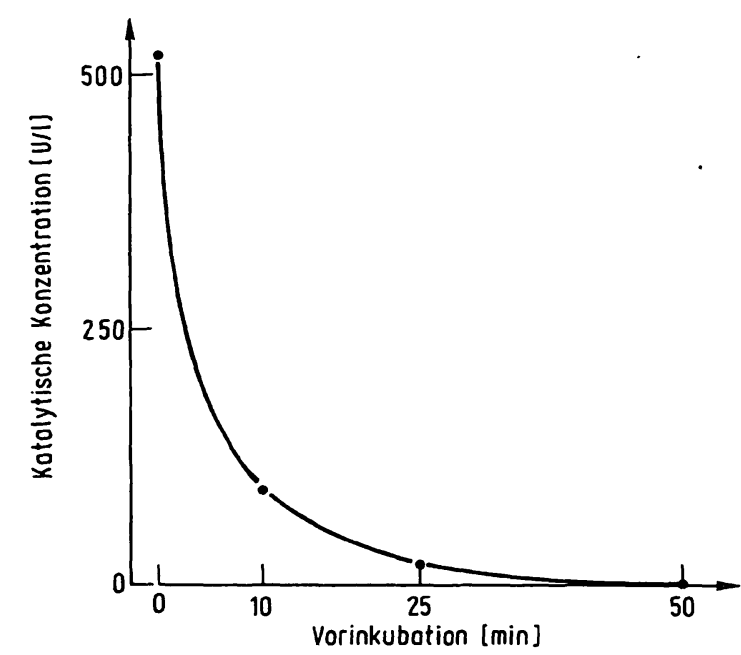

Abb. 18. Kontinuierlicher titrimetrischer Test mit Tween 20 als Substrat. Inaktivierung der Esterasen des Serums in Abhängigkeit von der Dauer der Vorinkubation mit Phenylmethylsulfonylfluorid in einer Endkonzentration von $3,3 \mathrm{mmol} / 1$.

\section{Diskussion}

Hochgereinigte Esterasen aus verschiedenen Organen hydrolysieren nicht nur Fettsäure-O-Ester, sondern auch die entsprechenden Thioester (Übersicht bei Krisch (6)). In Analogie dazu synthetisierten Kurooka et al. (7) auf der Suche nach einem geeigneten Substrat zur Bestimmung der Lipase etwa 100 Substanzen, in denen Thiolgruppen mit Fettsäuren unterschiedlicher Kettenlänge verestert sind. Unter diesen Thioestern fanden sie nur zwei, nämlich 2,3-Dimercapto-1-propanol-tributyrat und 3-Mercapto-1,2-propandiol-tributyrat, die mit ausreichender Geschwindigkeit von Schweinepankreaslipase hydrolysiert wurden. Später beschrieben Kurooka et al. sich, daß die Aktivität eines Serums von einem Patienten mit akuter Pankreatitis gegenüber Triolein auch nach 50 min langer Inkubation mit dem Hemmstoff in einer Endkonzentration von 3,3 mmol/1 innerhalb der Fehlerbreite der titrimetrischen Methode nicht verändert wird. Dieser Befund bestätigt gleichzeitig frühere Untersuchungen, in denen gezeigt wurde, daß Triolein durch Esterasen nicht umgesetzt wird (2).

Schließlich wurde die Wirkung von Na-Dodecylsulfat auf die Hydrolyse der beiden spezifischen Substrate untersucht. Während eine Hemmung der Esteräseaktivität durch Na-Dodecylsulfat im titrimetrischen Test erst in Gegenwart von mehr als $5 \mathrm{mmol} / \mathrm{l}$ des Netzmittels zu beobachten war, begann die Verminderung der Lipaseaktivität bereits bei einer Konzentration von $0,05 \mathrm{mmol} / \mathrm{l}$ (Abb. 19). In Gegenwart der von Kurooka et al. (1) empfohlenen Konzentration von 1,7 mmol/1 Na-Dodecylsulfat ist die Lipaseaktivität der Seren von Patienten mit akuter Pankreatitis auf weniger als $25 \%$ des Ausgangswertes in Abwesenheit von Na:Dodecylsulfat vermingdert.

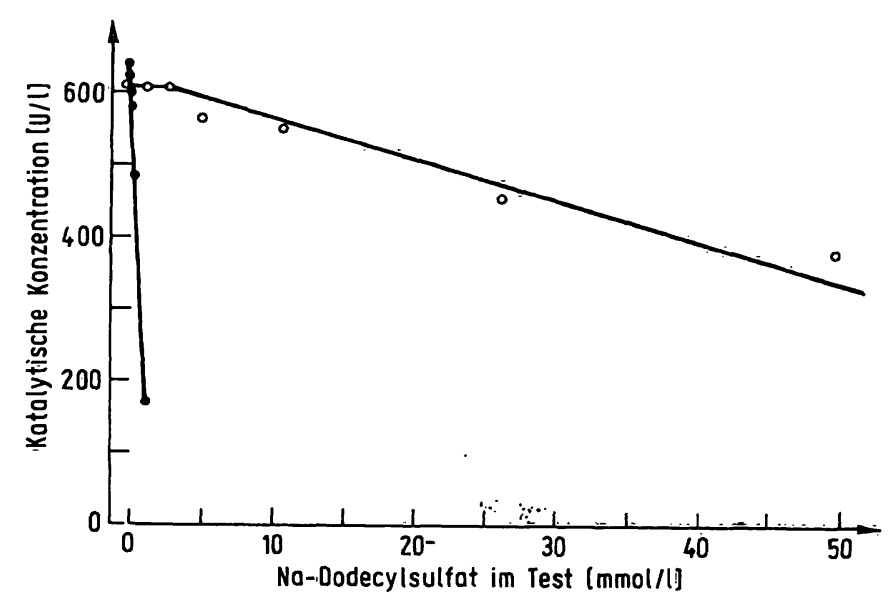

Abb. 19. Kontinuierlicher titrimetrischer Test mit Tween 20 bzw. Triolein als Substrat. Hemmung der Esterase- bzw. Lipase durch Natriumdodecylsulfat.

-—o Hydrolyse von Tween 20

- - Hydrolyse von Triolein

(1) einen photometrischen $Z$ weipunkttest mit 2,3-Dimercapto-1-propanol-tributyrat als Substrat und $5 ; 5^{\prime}$ Dithio-bis(2-nitrobenzoat) als Farbreagens. Da 2,3-Dimercapto-1-propanol-tributyrat unter anderem auch von den Arylesterasen des Serums und der Carboxylesterase aus Leber hydrolysiert wird, setżten die Autoren dem Ansatz Phenylmethylsulfonylfluorid als Inhibitor dieser Enzyme zu. Außerdem verwendeten sie $\mathrm{Na}$ Dodecylsulfat als „Aktivator" der Lipase.

Ob die enzymatische Hydrolyse von 2,3-Dimercapto-1propanol-tributyrat tatsächlich entsprechend dem von Kurooka et al. (1) angegebenen Schema unter Freisetzung von 3 Molekülen Buttersäure bis zum 2,3-Di- 
mercapto-1-propanol verläuft, wurde von den Autoren nicht nachgewiesen. Unabhängig davon entgehen die freigesetzten Hydroxylgruppen des 2,3-Dimercapto-1propanol dem Nachweis in der verwendeten Indikatorreaktion, die nur SH-Gruppen erfaßt.

Wir prüften den von Kurooka et al. (1) angegebenen Test zur Bestimmung der Lipase zunächst mit den kommerziell erhältlichen Reagentien. Im Gegensatz zur Stabilität des 2-Nitro-5-mercaptobenzoats in Acetonlösung (8) zeigte die Farbreagens-Gebrauchslösung unabhängig von Lichteinflüssen eine ständig zunehmende Gelbfärbung. Dieser Effekt spielt bei der Bestimmung der Cholinesterase im Serum mit Butyryl-thiocholiniodid als Substrat und mit Ellmans Reagens keine Rolle, da die Meßzeit bei dieser kontinuierlichen Methode nur wenige Minuten beträgt (9). Die spontane Gelbfärbung geht auch aus der Angabe des Herstellers hervor, daß nur 5,5'-Dithio-bis(2-nitrobenzoat)-Stammlösungen mit einer Absorption unter 1,0 bei $412 \mathrm{~nm}$ verwendet werden sollen.

Da Aceton den Nachteil hat, beim Stehen und vor allem beim Zentrifugieren der Ansätze zu verdunsten, so daß es zu Volumenänderungen kommt, suchten wir nach einer anderen geeigneten Substanz, die Substrat und Proteine in Lösung bringt und gleichzeitig die enzymatische Reaktion unterbricht. Unter zahlreichen geprüften Lösungsmitteln erwies sich nur Dimethylsulfoxid als verwendbar.

Die spektralen Eigenschaften des 2-Nitro-5-mercaptobenzoats verändern sich in Abhängigkeit vom Lösungsmittel. Während wäßrige Lösungen bei $412 \mathrm{~nm}$ maximal absorbieren (3), findet sich das Absorptionsmaximum bei Arbeit nach der Originalvorschrift in 63\% Aceton bei $426-428 \mathrm{~nm}$ und nach unserer Modifikation in 63\% Dimethylsulfoxid bei 440-446 nm. Im Gegensatz dazu empfehlen Kurooka et al. (1), auch die acetonhaltigen Ansätze bei $412 \mathrm{~nm}$ zu photometrieren.

Standardlösungen von 2,3-Dimercapto-1-propanol mit 5,5'-Dithio-bis (2-nitrobenzoat) in Anwesenheit von Aceton bzw. Dimethylsulfoxid ergaben in der geprüften Meßzeit bis zu 30 Minuten eine konstante Farbintensität. Ebenso zeigte sich nach Serumzugabe während des genannten Zeitraums keine Änderung der Absorption. Versetzt man jedoch Lösungen von 2,3-Dimercapto-1propanol-tributyrat in Abwesenheit von Serum mit 5,5'-Dithio-bis(2-nitrobenzoat)-Reagens und Lösungsmittel, so nimmt die Farbentwicklung ständig zu. Der Effekt ist in Ansätzen mit Dimethylsulfoxid stärker ausgeprägt. Setzt man den Testen Serum zu, so ist die Absorptionszunahme mit der Zeit in den Bestimmungsansätzen intensiver als in den Proben-Leerwerten; somit steigt auch die Absorptionsdifferenz leicht an. Dies macht es erforderlich, Haupt- und Leerwerte unmittelbar nach dem Zentrifugieren zu photometrieren; größere Serien können mithin nur durch Zusammenarbeit zweier Untersucher analysiert werden. Mögliche Ursachen für die Inkonstanz der Farbentwicklung wurden bereits mitgeteilt.

In Untersuchungen mit Variation der Inkubationszeit fanden wir eine deutliche lag-Phase der enzymatischen Reaktion (s. Abb. 1 und 2). Bei einem Teil der geprüften Seren war es möglich, diese lag-Phase durch Zusatz von Na-Glykocholat zu beseitigen (s. Abb. 4). Gleichzeitig führte das Gallensalz teilweise zu geringen Aktivitätssteigerungen. Da jedoch höhere Glykocholatkonzentrationen in Abhängigkeit von der Inkubationszeit mehr oder weniger rasch eine Hemmwirkung auf die Hydrolyse von 2,3-Dimercapto-1-propanol-tributyrat zeigten (s. Abb. 3 und 4), war es nicht möglich, Bedingungen auszuarbeiten, bei denen an verschiedenen Seren mit unterschiedlicher Lipaseaktivität während 30 Minuten in jedem Fall ein linearer Reaktionsablauf erzielt wird.

Die lag-Phase bei dem von Kurooka et al. (1) angegebenen Verfahren ist auch die Ursache dafür, daß bei Einsatz von Serumverdünnungen keine Proportionalität zwischen dem eingesetzten Probevolumen und der gemessenen Absorption bestehen kann. Wird physiologische $\mathrm{NaCl}$-Lösung als Verdünnungsmittel benutzt, werden mit abnehmendem Serumgehalt zu niedrige Absorptionen gefunden (s. Abb. 6). Verdünnungen der zu untersuchenden Probe mit inaktiviertem Sammelserum ergeben eine andere, jedoch ebenfalls nicht lineare Beziehung zwischen Probenmenge und Meßsignal (s. Abb. 9). Auch bei der Analyse von Probenverdünnungen ließ sich durch Zusatz von Gallensäuren keine grundlegende Verbesserung erzielen. Die komplizierten Zusammenhänge sind in den Abbildungen 7, 8, 10 und 11 dargestellt. Die Empfehlung von Kurooka et al. (1), Seren mit hohem Lipasegehalt mit Normalserum zu versetzen, ist von der enzymatischen Reaktion her nicht zu begründen. Wenn Matrixeffekte beim Verdünnen von Bedeutung sein sollten, so ist es schwer vorstellbar, daß sich diesbezüglich Normalseren und solche, bei denen die lipolytische Aktivität durch Erhitzen bei $+56{ }^{\circ} \mathrm{C}$ beseitigt wurde, wesentlich unterscheiden.

Wegen der fehlenden Linearität zwischen Probevolumen im Test und Meßsignal ist eine Umrechnung der Meßwerte in katalytische Konzentrationen (Dimension U/l) nicht zulässig.

Da es notwendig ist, die esterolytischen Enzyme des Serums, die 2,3-Dimercapto-1-propanol-tributyrat ebenfalls hydrolysieren, zu hemmen, prüften wir die Bedingungen, unter denen diese störenden Aktivitäten beseitigt werden sollen. Folgt man der Originalvorschrift und inkubiert reine Schweineleberesterase mit dem Hemmstoff Phenylmethylsulfonylfluorid in Gegenwart von Ellmans Reagens, so bleibt unabhängig von der Inkubationszeit und der Inhibitorkonzentration eine Restaktivität erhalten. Diese unvollständige Hemmung der Carboxylesterase beruht darauf, daß der Inhibitor im Gemisch mit 5,5'-Dithio-bis(2-nitrobenzoat) zunehmend 
unwirksam wird. Läßt man Phenylmethylsulfonylfluorid direkt auf die Esteraselösung einwirken, so ergibt sich die typische Hemmcharakteristik (s. Tab. 5). Verwendet man Tween 20 als Substrat der Esterasen im Serum, so ist eine etwa 50 Minuten dauernde Vorinkubation des Serums mit Phenylmethylsulfonylfluorid in einer Endkonzentration von $3,3 \mathrm{mmol} / \mathrm{l}$ erforderlich, um die esterolytische Aktivität vollständig zu hemmen. Unter den von Kurooka et al. (1) empfohlenen Bedingungen ist mithin die Interferenz durch Esterasen nicht behoben, so daß die Methode nicht spezifisch nur die Lipase des Serums erfaßt.

Die Bedeutung der oberflächenaktiven Substanz NaDodecylsulfat im Testsystem mit 2,3-Dimercapto-1propanol-tributyrat als Substrat konnte nicht geklärt werden. Im kontinuierlichen titrimetrischen Test mit Triolein als Substrat (2) wirkt Na-Dodecylsulfat schon in einer Konzentration von 0,05 mmol/l hemmend; die Aktivität im Serum von Pankreatitiskranken ist in Gegenwart von $1,0 \mathrm{mmol} / 1 \mathrm{Na}$-Dodecylsulfat auf etwa $50 \%$ herabgesetzt (Abb. 19). Im Gegensatz dazu wird die Farbintensität bei dem von Kurooka et al. (1) beschriebenen Verfahren durch Na-Dodecylsulfat außerordentlich gesteigert (s. Abb. 16 und 17). Bei diesem Effekt handelt es sich daher vermutlich nicht um eine „Aktivierung“ der Lipase, sondern möglicherweise um eine Änderung der Indikatorreaktion durch die oberflächenaktive Substanz.

Trotz der oben aufgezeigten Probleme und Unklarheiten im Ablauf der Enzym- und Indikatorreaktion führten wir Vergleichsuntersuchungen an 104 Seren mit normaler oder leicht erhöhter Lipase aus. Wie zu erwarten, ergaben sich signifikante Abweichungen zum kontinuierlichen titrimetrischen Test mit Triolein als Referenzmethode (s. Abb. 13 und 14). Der in beiden Darstellungen auffällig große Ordinatenabschnitt dürfte u.a. durch die beschriebene lag-Phase bei dem Verfahren mit 2,3-Dimercapto-1-propanol-tributyrat als Substrat bedingt sein.
Abschließend ist festzustellen, daß bei der von Kurooka et al. (1) beschriebenen Methode erhebliche Verbesserungen erforderlich sind, wenn damit im Einzelfall klinisch relevante Ergebnisse erzielt werden sollen. Folgende Punkte erscheinen besonders wichtig:

i 1

1. Es sollte versucht werden, ein für Lipase spezifisches Substrat - z. B. 2,3-Dimercapto-1-propanol-trioleat zu verwenden, um die Probleme der unvollständigen Hemmung von Esterasen durch Phenylmethylsulfonylfluorid auszuschalten.

2. Die Farbreagens-Gebrauchslösung darf keine Änderung der Farbintensität mit der Zeit zeigen.

3. Die Zunahme der Gelbfärbung in fertigen Testansätzen und der leichte Anstieg der Absorptionsdifferenz ist auszuschalten.

4. Störungen durch die lag-Phase sollten beseitigt werden.

5. Die Testbedingungen sind șo zu wählen, daß Verdün= nungen von Seren mit hohem Lipasegehalt analysiert werden können.

6. Eingehende Untersuchungen über die komplizierten Wechselwirkungen zwischen den Komponenten des Tests (Substrat, Ethanol, Na-Dodecylsulfat, Gallensäuren, Proteine u.a.) an verschiedenen Patientenproben sind erforderlich.

7. Linearität zwischen eingesetztem Probevolumen und Meßsignal in einem weiten Bereich ist Voraussetzung dafür, daß die Meßwerte in katalytische Aktivitäten (U/l) umgerechnet werden können.

\section{Danksagung}

Wir danken Herrn Dr. S. Kurooka für die frẹndliche Überlassung von 2,3-Dimercapto-1-propanol-tributyrat.

\section{Literatur}

1. Kurooka, S., Okamoto, S. \& Hashimoto, M. (1977) J. Biochem. Tokyo 81, 361-369.

2. Rick, W. (1976) Lipase. In: Handbuch der Inneren Medizin (Forell, M. M. ed.). 5. Aufl. Bd. III/6: Pankreas. Springer, Berlin pp. 350-361.

3. Ellman, G. L. (1959) Arch. Biochem. Biophysics 82, 70-77.

4. Lorentz, K., Flatter, B. \& Augustin, E. (1979) Clin. Chem.

$25,1714-1720$.

5. Rick, W. \& Hockeborn, M., in Vorbereitung.

6. Krisch, K. (1971) Carboxylic ester hydrolases. In: The Enzymes (Boyer, P. D. ed.). Academic Press, New York, Vol. 5, pp. 43-69.

7. Kurooka, S., Hashimoto, M., Tomita, M., Maki, A. \& Yoshimura, Y. (1976) J. Biochem. Tokyo 79, 533-541.

8. Kurooka, S. (1979) pers. Mitteilung.

9. Knedel, M. \& Böttger, R. (1967) Klin. Wochenschr. 45, 325327.

Prof. Dr. W. Rick Institut für Klinische Chemie und Laboratoriumsdiagnostik der Universität Düsseldorf Moorenstraße 5 D-4000:Düsseldorf 1 